\title{
Capital Intensity and Investment Shocks: Implications for Stock Returns
}

\author{
Jiri Knesl *
}

May 6, 2019

\begin{abstract}
I show that a firm's capital intensity affects the asset pricing implications of investment-specific technology shocks measured by a popular measure, the IMC porfolio. Capital-intensive stocks sorted by the exposure to this measure generate a highly significant average return premium of up to $5 \%$ annually. A similar return premium is present in the sub-sample of capital-intensive firms but absent among labor-intensive firms, while the exposures to the IMC portfolio are similar in both sub-samples. This finding is a puzzle since similar exposures to this measure of investment shock generate a very different return premium for capital-intensive and labor-intensive firms. To explain this puzzle, I extend prior models of the investment-specific technology shocks by a novel dimension; firm's capital intensity. The model can rationalize these empirical findings.
\end{abstract}

\footnotetext{
* Jiri Knesl is a PhD student at the University of British Columbia. I thank Lorenzo Garlappi, Adlai Fisher, Jan Bena, Murray Carlson, Jesse Perla and Zhongzhi Song for their support, comments and providing data and infrastructure. I thank Alexander Barinov (discussant) and participants at the NFA Doctoral Session 2017 for helpful comments. The remaining errors are my own.
} 


\section{Introduction}

Technological innovations have been identified as the main driver of economic growth, Greenwood, Hercowitz, and Krusell (1997) 1 A large part of technological innovations is embodied in the formation of new capital and has been labeled as investment-specific technology shocks (IST), or more concisely, investment shocks. Recent finance literature, e.g. Papanikolaou (2011), suggests that investment shocks can also affect expected stock returns. Hence, measuring firm's exposure to these shocks is crucial for understanding the relationship between firms' expected stock returns and the associated sources of risk.

In this paper, I study how firm's capital intensity relates to the measurement of firms exposure to these shocks using a popular measure, the IMC portfolio. An intuition based on previous literature suggests that technological innovations embodied in new capital are expected to be relevant especially for capital-intensive firms as capital is the key production factor for these firms. In contrast, labor-intensive firms are expected not to be directly affected by such innovations. ${ }^{2}$

I show that the pattern documented by previous literature, e.g. Kogan and Papanikolaou (2014), of decreasing abnormal stock return of stocks sorted by the exposure to the IMC portfolio is present among capital-intensive firms, but it is almost absent among labor-intensive firms. This suggests that the documented pattern is driven mainly by firms in the first sub-sample. Specifically, I divide the cross-section of firms into capital-intensive and labor-intensive firms. I use the IMC portfolio as an empirical measure of investment shocks based on the return spread between investment-goods and consumption-goods firms, as proposed by Papanikolaou (2011). While sorting the firms by their exposure to the IMC portfolio gives a statistically significant abnormal return of $5 \%$ among capitalintensive firms, the same sorting among labor-intensive firms leads to insignificant abnormal return of low magnitude. Interestingly, the estimated exposures to the IMC portfolio span approximately the same range in capital-intensive and labor-intensive firms. This result is puzzling since the same exposure to the IMC portfolio seems to be priced differently among each types of firms.

I provide a potential explanation for these observations. The IMC portfolio is intended to measure the IST shocks, a risk that is assumed to carry negative premium. At the same time, the IMC portfolio has an empirically strong and positive exposure to the market risk and the size factor (SMB), both of which are priced positively. Labor-intensive firms, in general, use only limited capital and their exposure to the IMC portfolio does not arise due to their exposure to the investment shocks but due to other reasons, e.g., an exposure to the market and size factors. In contrast, capital-intensive firms use large amounts of and hence their exposure to the IMC portfolio can arise due mainly to their exposure to the investment shocks. In such setting, the IMC portfolio can be a reasonable proxy for measuring the exposure to the investment shocks among capital-intensive firms but fails to capture this exposure among labor-intensive firms. Since the IMC

\footnotetext{
1 Greenwood, Hercowitz, and Krusell (2000); Fisher (2006); Justiniano, Primiceri, and Tambalotti (2010) also identify the investment-specific technology shocks as a major source of business-cycle fluctuation.

${ }^{2}$ This statement is based on the assumption that firms do not substitute between capital and labor and the price (and productivity) of labor is not affected by investment-specific technology shocks.
} 
portfolio is an easily available measure of investment shocks that is available at high frequency it is important to understand its capability.

I extend the existing models of the investment-specific technology shocks in a simple and tractable fashion to illustrate the economic mechanisms and to analyze the quantitative aspects. I study the asset pricing implications of a firm's capital intensity in a framework with both the total productivity (disembodied) technology shock and the investment-specific (embodied) technology shock, building on the two-sector model from Kogan and Papanikolaou (2014). This model consists of consumption-goods and investment-goods producers and differentiates between the factor neutral and the investment-specific shocks. The novel aspects of my model are firms with different capital (or labor) intensities, their potential to resale obsolete capital, and wage rigidity.

I focus on two sub-samples of firms, one consisting of firms with a high capital-labor ratio and one of firms with a low capital-labor ratio. Capital intensity creates a difference in the exposure of firms' growth opportunities to the investment shocks between capital-intensive and labor-intensive firms. In the model, capital-intensive firms use larger amounts of capital in their (potential) production and hence their growth opportunities are exposed to the investment shocks, which change the price of capital. Wage rigidity generates operating leverage and makes a firm more exposed to market risk. Since labor-intensive firms tend to optimally choose higher use of labor, they have the capacity to be highly levered and be exposed to the aggregate risk more than capital-intensive firms.

In the model, I allow the IMC portfolio to be positively correlated with both the aggregate risk and investment shocks as documented by empirical evidence. In such setting, both capitaland labor-intensive firms can have high exposure to the IMC portfolio while different exposures to the investment shock. The model can generates high abnormal return for capital-intensive stocks sorted on their exposure to the IMC portfolio and a considerably smaller abnormal return for labor-intensive firms.

This paper contributes to two streams of literature. First, a large part macroeconomic literature studies the implications of investment shocks for growth and other macroeconomic variables. Representative papers in this area are Greenwood et al. (1997), Greenwood et al. (2000) and Fisher (2006). They show that investment shocks account for a large part of economic growth as well as for variations in output and other macroeconomic variables. Justiniano et al. (2010) show that investment shocks are the main driver for business cycle fluctuations. Greenwood, Hercowitz, and Huffman (1988) investigates the role of capacity utilization for business cycles and positive correlation between macroeconomic variables in a model with investment-specific shocks. Second, investment shocks have become an active research area in financial economics. Papanikolaou (2011) is the first to study the implications of investment shocks for asset prices both on aggregate and in the cross-section. ? study the implications of capital utilization and market power for pricing assets exposed to investment shocks. Kogan and Papanikolaou (2013) and Kogan and Papanikolaou (2014) focus on the implications of investment shocks for growth options, investments and several return anomalies. Garlappi and Song (2016) examine empirically how various measures of the investment shocks price a range of cross-sectional return anomalies. Garlappi and Song (2018) 
use data on firms' investment to infer firms' exposure to the investment shocks.

I differ from this literature in that I introduce to the prior asset pricing models with investment shocks a novel dimension, firms' capital intensity. In such extended model, the capital intensity determines the exposure of a firm's growth opportunities to investment shocks and hence also the riskiness of the whole firm. I further allow the measure of investment shocks, the IMC portfolio, to correlate with market returns as observed in the data as well as partially rigid wages. These extensions to the model are helpful as they allow the model to further examine the role of investment shocks for firms' growth opportunities and the estimation of their exposure to these shocks based on the IMC portfolio.

The paper proceeds as follows. Section III describes the data and first empirical results. Section III] shows the extended model. In section IV] I derive the empirical implications and provide supportive empirical evidence. I describe the calibration and simulation results in section $\mathrm{V}$ and conclude in section VI.

\section{Data and Empirical Evidence}

\section{A. Data}

The data on stock prices are from CRSP. I use the universe of ordinary common stocks $(\operatorname{shrcd}=10,11)$ of firms traded on NYSE, AMEX and NASDAQ (exchcd=1,2,3) in the time period from 1950 to 2015. I exclude financial firms (SIC 6000-6799) and utilities (SIC 4900-4949). In order to categorize the firms into investment-goods producers and consumption-goods producers, I follow the previous literature (Garlappi and Song (2016), Gomes, Kogan, and Yogo (2009) and Papanikolaou (2011)) and use the NIPA Input-Output tables from 1987 and categorize the firms into investment-goods and consumption-goods producers based on their contribution to each sector. Accounting data are from Compustat. I measure firm's capital intensity by the number of employees over property, plant and equipment $\left(\frac{e m p_{f, t}}{\text { ppegt }_{f, t}}\right)$.

Table III shows the summary statistics of firms categorized into investment-goods and consumptiongoods sector. The investment-goods sector is smaller than the consumption-goods sector 3 The firms in the consumption-goods sector are similar to firms in the investment-goods sector in terms of book-to-market equity ratio and cash flow-to-assets ratio, but differ slightly in operating leverage, capital, number of employees and capital-labor ratio. These differences, however, are rather small compared to the $10 t h$ and $90^{\text {th }}$ percentiles of these variables.

I construct the IMC portfolio following the methodology in Kogan and Papanikolaou (2014) and Garlappi and Song (2016). First, I calculate the value-weighted return for portfolios consisting of investment-goods firms (I-portfolio) and consumption-goods firms (C-portfolio), respectively. Then, I create the IMC (Investment Minus Consumption), consisting of long position in the I-portfolio and short position in the C-portfolio. Since this measure of the IST shock is based on stock returns,

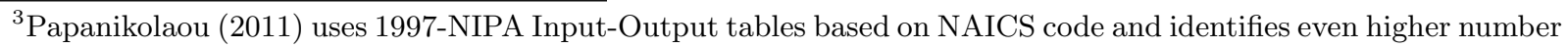
of firms in the consumption-goods sector.
} 
it is available at the frequency of stock returns. For further analysis, I use monthly stock returns.

I estimate the exposure of each consumption-goods firm to the IMC portfolio by estimating the $\beta_{f, t}^{I M C}$ from following regression equation:

$$
R_{f, t}-R^{\text {riskfree }}=\alpha_{f, t}+\beta_{f, t}^{I M C} \times R_{t}^{I M C}+\epsilon_{f, t} .
$$

I use a rolling and overlapping window of monthly returns over the last 60 months. Accordingly,

firm $f^{\prime} s \beta_{f, t}^{I M C}$ at time $t$ is estimated from monthly returns ranging from $t-60$ to $t-1.4$ The betas are updated annually at the end of June.

I sort the stocks by their estimated $\beta_{f, t}^{I M C}$ into 5 portfolios annually at the end of June. The return of each portfolio is the weighted average return of the stocks in that portfolio. I construct the time series of the portfolios from 1970 to 2015. Following the existing literature, e.g., Kogan and Papanikolaou (2013, 2014), I focus on the universe of consumption-goods stocks.

Table 1 shows the pairwise correlation coefficients between the IMC portfolio and the market excess return, and the $S M B$ and $H M L$ factors. Th IMC portfolio is negatively correlated ($0.25)$ with the value factor $H M L$ which is consistent with the intuition in Kogan and Papanikolaou (2014), which is described later in the text. The IMC portfolio, however, is also positively correlated with the two other factors, namely the market return and the $S M B$ with correlation coefficient of 0.45 in both cases. This suggests that sorting stocks by their $\beta_{f, t}^{I M C}$ is likely to capture exposure to these two factors as well. Stocks which have generally higher exposure to market and $S M B$ will tend to have a higher $\beta_{f, t}^{I M C}$.

\section{B. $\quad \beta^{I M C}$ Sorting}

First I focus on the return pattern of portfolios sorted by their exposure to the investment shock. Table II presents the return characteristics of portfolios sorted by the exposure to the IMC portfolio based on the $\beta^{I M C}$ estimated from a univariate regression, which is the standard in previous literature. Panel A shows that sorting stocks by the $\beta_{f, t}^{I M C}$ creates only a very weak decreasing pattern in average excess returns. The estimates in panel B show that the abnormal return $\alpha$ decreases more strongly across the portfolios due mostly to the increasing loadings on the market return. The difference in $\alpha$ between the portfolios at each end amount to statistically significant 6.48\%. Papanikolaou (2011); Kogan and Papanikolaou (2014) first document this pattern and show that the decreasing returns coincide with a decreasing exposure to the $H M L$ portfolio creating a possible relationship between firms' growth opportunities and the exposure to the IMC portfolio.

In Panel C, I regress the portfolio returns onto the ? three factors, the market, $S M B$, and $H M L$. The loadings on the $H M L$ factor are not significant for the first four portfolio but strongly negative for portfolio five indicating that firms with high exposure to the IMC portfolio have more growth opportunities. The HL portfolio, then, has a significant and negative exposure to the $H M L$

\footnotetext{
${ }^{4}$ Kogan and Papanikolaou (2014) show that it is possible to use also weekly returns which highlights the advantage of a high frequency measure.
} 
factor. The loadings on the market and the $S M B$ factors are increasing across the portfolios, so that the HL portfolio has a significantly positive exposure to these two factors. This is consistent with the evidence of a positive correlation between the IMC portfolio and these two factors shown in table I suggesting that sorting by the $\beta^{I M C}$ will result in sorting on the exposure to these two factors as well.

It is interesting to observe that the pattern of the abnormal returns, $\alpha$, is also present when the market, $S M B$, and $H M L$ factors are included. Although the original model of Kogan and Papanikolaou (2014) creates a potential link between firm's exposure to investment shocks and its growth opportunities, the extended model later in this text shows that a firm can have a differential exposure to investment shocks due to the potential resale of its capital regardless of its growth opportunities.

Panel D shows the median sorting $\beta^{I M C}$ of each portfolio together with the portfolios' estimated post-sorting exposure to the IMC portfolio. The post-sorting exposures are estimated from an univariate regression with monthly portfolio returns. The clearly increasing pattern of both, the sorting and post-sorting exposures, shows that sorting stocks into portfolios based on $\beta^{I M C}$ translates the exposure to the IMC portfolio to subsequent portfolio returns.

\section{Capital Intensity and $\beta^{I M C}$ Sorting}

I divide the universe of the consumption-goods firms into a sub-sample of capital-intensive firms and a sub-sample of labor-intensive firms to analyze the patterns of the abnormal returns in each sample separately. The motivation for this approach is based on the intuition that the growth opportunities of capital-intensive firms would be more sensitive to technological shocks embodied in capital goods. I measure the capital-intensity of each firm by the ratio of its capital to the

number of employees, $\frac{\text { ppegt }_{f, t}}{\text { employees }_{f, t}}$, where $p p e g t_{f, t}$ stands for firm $f^{\prime} s$ property, plant and equipment in yea $t$. I allocate the firm into capital-intensive sub-sample if its capital-intensity is above the cross-sectional median in year $t$ and into labor-intensive if it is below.

Table IV] shows the summary statistics of the capital-intensive and labor-intensive sub-samples for firms in consumption-goods, investment-goods sector as well as both sectors together. Capitalintensive firms are generally bigger as their market capitalization is about two to three times higher than the market capitalization of labor-intensive firms. Obviously, capital-intensive firms differ from labor-intensive firms in their capital-labor ratio. Interestingly, these differences are driven especially by the numerator of this ratio, capital, as both types of firms tend to have comparable number of employees. It is important to observe that the book-to-market ratio and its ranges are comparable for capital-intensive and labor-intensive firms. In contrast, the operating leverage and the difference between its $90^{t h}$ and $10^{t h}$ percentile are higher for labor-intensive firms than for capital-intensive firms.

Next, I sort the firms in each sub-sample into quintile portfolios by their $\beta_{f, t}^{I M C}$ as in previous sections. Table $\mathrm{V}$ reports the return characteristics of the portfolios sorted by $\beta^{I M C}$ in each subsample. Panel A shows a stronger pattern of decreasing excess returns across the portfolios of 
capital-intensive firms than observed above. In contrast, the average excess returns are increasing across te $\beta^{I M C}$ sorted portfolios for labor-intensive firms. The estimates in panel B show that the abnormal return. $\alpha$, is exhibits very strong and decreasing pattern for capital-intensive firms which is even slightly stronger that the pattern observed in the full sample. The $\alpha$ of the long-short, HL, portfolio amounts to $-7.56 \%$ at per year. Such pattern is, however, considerably weaker among labor-intensive firms. The $\alpha$ of the long-short portfolio is only $-2.87 \%$ per year in this sub-sample. This suggests that the pattern in $\alpha$ identified in the previous section is driven by capital-intensive firms.

Panel $\mathrm{C}$ shows the estimated loading on the market, $S M B$ and $H M L$ factors. The loadings of the portfolios on the $H M L$ factor decrease across the portfolios more in the labor-intensive than in the capital-intensive sub-sample. At the same time capital-intensive firms exhibit somewhat higher differences in the loadings on the $S M B$ factor. This observation may suggests that a relatively low growth opportunities of the capital-intensive long-short portfolio (a negative exposure to the $H M L$ factor of only -0.31) is sufficient to result in a large abnormal return $\alpha$ despite a large exposure to the $S M B$ factor. In contrast, labor-intensive HL portfolio seems exhibit much higher growth opportunities (negative loading to the $H M L$ factor of -0.59) but earns considerably smaller $\alpha$.

Panel D then shows portfolios in both sub-samples have almost the same pattern in their exposure to the IMC portfolio. This results is puzzling for two reasons. First, the same loading of the HL capital- and labor-intensive portfolios on the IMC portfolio result in very different $\alpha$. Second the capital- and labor-intensive HL portfolios have also very different exposure to the $H M L$ factor despite having almost the same exposure to the IMC portfolio. The loading of the HL portfolio on the market risk is comparable for both sub-samples, but the Capital-intensive firms with high exposure to the IMC portfolios earn lower average and abnormal returns than capital-intensive firms with low exposure to investment shock. The model in the subsequent section will seek to reconcile these discrepancies by the differences in firms' capital intensity.

\section{The Model}

Motivated by the empirical evidence, I build on the partial-equilibrium model of Kogan and Papanikolaou (2014) (KP) and extend it by introducing capital-intensity and the potential resale of firms' existing assets to see whether these two dimensions can reconcile the empirical observations. KP model the cross-section of consumption-goods firms, while the investment-goods firm is modeled in a simplified reduced form so that the model is able to generate the IMC portfolio as a potential measure of an investment shock. The extension I add to the model allow three things. First the IMC portfolio can be exposed not only to the investment shocks but also the a factor-neutral aggregate productivity shock. Second, they further allow to analyze the potential bias in the $\beta^{I M C}$ as a measure of a firm's exposure to investment shocks. Third, they allow to examine how capitalintensity can alter the link between a firm's growth opportunities and its exposure to the investment shocks. 


\section{A. The Cash Flow of Consumption-Goods Firms}

The universe of the consumption-goods firms consists of two sectors $s \in\{L, H\}$, where $\mathrm{L}$ and $\mathrm{H}$ denotes the low and high capital intensive firms, respectively. Each of these two sectors consists of set of firms $F_{s}$. Each firm consists of an individual number of projects enumerated by $j \in J_{t}^{f}$. Firms create projects by investment in productive capital and by hiring labor when a new project opportunity arrives. Project $j$ owned by firm $f$ in sector $s$ generates output equal to:

$$
y_{f, j, t}=\epsilon_{f, t} u_{j, t} x_{t} K_{j}^{\alpha_{s}} L_{j}^{1-\hat{\alpha}_{s}}
$$

, where $\epsilon_{f, t}$ is a firm-specific shock affecting all project owned by firm $f, u_{j, t}$ is a project-specific shock affecting only project $j$, and $x_{t}$ is an aggregate shock affecting all projects of all firms. The firm- and project-specific shocks are governed by mean-reverting processes, while the aggregate shock evolves as geometric Brownian motion to simulate aggregate growth:

$$
\begin{aligned}
d \epsilon_{f, t} & =-\theta_{\epsilon}\left(\epsilon_{f, t}-1\right) d t+\sigma_{\epsilon} \sqrt{\epsilon_{f, t}} d B_{f, t} \\
d u_{j, t} & =-\theta_{u}\left(u_{j, t}-1\right) d t+\sigma_{u} \sqrt{u_{j, t}} d B_{j, t} \\
d x_{t} & =\mu_{x} x_{t} d t+\sigma_{x} x_{t} d B_{x, t}
\end{aligned}
$$

$\alpha_{s}$ and $\hat{\alpha}_{s}$ determine the capital intensity of the firms in each sector $s$. Holding $\hat{\alpha}_{s}-\alpha_{s}$ fixed across both sectors, $\alpha_{s}$ is higher for capital-intensive sector. Moreover, $\alpha_{s}+\left(1-\hat{\alpha}_{s}\right)<1$ to suffice

decreasing returns to scale. New capital $K_{j, t}$ can be acquired at price $x_{t} z_{t}^{-1}$, where $z_{t}$ represents the investment shock and is governed by geometric Brownian motion:

$$
d z_{t}=\mu_{z} z_{t} d t+\sigma_{z} z_{t} d B_{z, t}
$$

The projects expire randomly according to Poisson process with a constant arrival rate $\delta$. When the project expires, the capital will be re-sold at the current price of capital to other firms demanding capital.

The total cash flow of the project consists of three components, (i) cash inflow generated by production $C F I_{j, t}$, (ii) cash outflow due to labor cost $C F O_{j, t}$ and (iii) cash inflow from capital re-sale $R S_{j, t}$ when the project expires. The value of each of this components is derived later in the text.

The stochastic discount factor is defined exogenously and is motivated by Papanikolaou (2011):

$$
\frac{d \pi_{t}}{\pi_{t}}=-r d t-\gamma_{x} d B_{x, t}-\gamma_{z} d B_{z, t}
$$

This specification includes two priced shocks, the aggregate shock $x_{t}$ with price $\gamma_{x}>0$ and the investment shock $z_{t}$ with price $\gamma_{z}<0$, where the sign of the price of each shock is based on the assumption in Kogan and Papanikolaou (2014). 
Time $t$ value of cash inflow generated by an existing project $\mathrm{j}$ is:

$$
\begin{aligned}
C F I_{j, t}\left(\epsilon_{f, t}, u_{j, t}, x_{t}, w, K_{j}, L_{j}\right) & =\mathbf{E}_{t}\left[\int_{t}^{\infty} e^{-\delta(s-t)} \frac{\pi_{s}}{\pi_{t}} \epsilon_{f, s} u_{j, s} x_{s} K_{j}^{\alpha_{s}} L_{j}^{1-\hat{\alpha}_{s}} d s\right] \\
& =A\left(\epsilon_{f, t}, u_{j, t}\right) x_{t} K_{j}^{\alpha_{s}} L_{j}^{1-\hat{\alpha}_{s}}
\end{aligned}
$$

, where

$$
\begin{aligned}
A= & {\left[\frac{1}{r+\gamma_{x} \sigma_{x}+\delta-\mu_{x}}+\frac{\epsilon_{f, t}-1}{r+\gamma_{x} \sigma_{x}+\delta-\mu_{x}+\theta_{\epsilon}}\right.} \\
& \left.+\frac{u_{j, t}-1}{r+\gamma_{x} \sigma_{x}+\delta-\mu_{x}+\theta_{u}}+\frac{\left(u_{j, t}-1\right)(\epsilon-1)}{r+\gamma_{x} \sigma_{x}+\delta-\mu_{x}+\theta_{u}+\theta_{\epsilon}}\right]
\end{aligned}
$$

I assume inelastic labor (i.e., infinite supply of labor for a given wage). The wage is given exogenously and has the same dynamics as the aggregate shock, so that the wage is

$$
W_{t}=w * x_{t},
$$

where $w$ is a positive constant. This assumption is reasonable for this type of partial-equilibrium model 15 I assume that a fraction of the hired labor force, $v$, has flexible wage, i.e. their wage evolves stochastically over the project lifetime as specified in formula (10). The remaining fraction $1-v$ has a rigid wage, i.e. the wage of this labor force is locked to the wage level at the arrival of the project $\left(T_{j}\right)$ and stays so for the project's lifetime. The parameter $v$ allows to model a degree of wage rigidity in a tractable way without a time dependence.

In this model, the wage rigidity creates an operating leverage and helps to differentiate between the riskiness of firms in each sector $s$. In the data, capital-intensive and labor-intensive firms differ. Labor-intensive firms tend to be smaller, have higher volatility of returns, and higher exposure to market return and to the $S M B$ factor. All this tends to increase the riskiness of firm and their exposure to positively priced factors. For the sake of simplicity of the model, I use operating leverage as the only source of a potentially different exposure of labor-intensive firms to the aggregate shock $x_{t}$. The time $t$ value of labor cost of an existing project $j$ is:

$$
\begin{aligned}
C F O_{j, t} & =\mathbf{E}_{t}\left[\int_{t}^{\infty} v e^{-\delta(s-t)} \frac{\pi_{s}}{\pi_{t}} x_{s} w L_{j}+(1-v) e^{-\delta(s-t)} \frac{\pi_{s}}{\pi_{t}} x_{T_{j}} W_{s} L_{j} d s\right] \\
& =\left[v x_{t}\left(B^{f l e x}\right)^{-1}+(1-v) x_{T_{j}}\left(B^{r i g}\right)^{-1}\right] w L_{j},
\end{aligned}
$$

where $\left(B^{\text {flex }}\right)^{-1}=\frac{1}{r+\gamma_{x} \sigma_{x}+\delta-\mu_{x}},\left(B^{r i g}\right)^{-1}=\frac{1}{r+\delta}$ and $x_{T_{j}}$ is the level of aggregate productivity at the time of project $j^{\prime} s$ arrival, so that the wage for the project $j^{\prime} s(1-v)$ fraction of labor force is constant at $x_{T_{j}} w$.

\footnotetext{
${ }^{5}$ In general equilibrium, the wage would be determined by supply of labor from household and demand of labor from the firms.
} 
The expected time $t$ value of the cash flow from the capital re-sale is:

$$
R S_{j, t}=\mathbf{E}_{t}\left[\int_{t}^{\infty} \delta e^{-\delta(s-t)} \frac{\pi_{s}}{\pi_{t}} x_{s} z_{s}^{-1} K_{j}\right]=x_{t} z_{t}^{-1} M K_{j}
$$

where $M=\frac{\delta}{r+\delta+-\mu_{x}+\mu_{z}-\sigma_{z}^{2}+\gamma_{x} \sigma_{x}-\gamma_{z} \sigma_{z}}$.

The time $t$ value of project $j$ is the sum of all cash flow components, cash inflow, re-sale, and cash outflow, generated by the project:

$$
\begin{aligned}
p\left(\epsilon_{f, t}, u_{j, t}, x_{t}, z_{t}, w, K_{j}, L_{j}\right)= & C F I_{j, t}+R S_{j, t}-C F O_{j, t} \\
= & A\left(\epsilon_{f, t}, u_{j, t}\right) x_{t} K_{j}^{\alpha_{s}} L_{j}^{1-\hat{\alpha}_{s}}+x_{t} z_{t}^{-1} M K_{j} \\
& -\left[v x_{t}\left(B^{f l e x}\right)^{-1}+(1-v) x_{T_{j}}\left(B^{r i g}\right)^{-1}\right] w L_{j} .
\end{aligned}
$$

New projects arrive to each firm randomly according to a Poisson process with a firm-specific arrival rate $\lambda_{f, t}$. The firm-specific arrival rate itself is a random variable:

$$
\lambda_{f, t}=\lambda_{f} \times \tilde{\lambda}_{f, t}
$$

where $\lambda_{f}$ is a firm-specific constant and $\tilde{\lambda}_{f, t}$ underlies two-state Markov process with values $\tilde{\lambda}_{f, t} \in$ $\left\{\lambda_{H}, \lambda_{L}\right\}$ and with transition probability matrix (between $\mathrm{t}$ and $\mathrm{t}+\mathrm{dt}$ ):

$$
P=\left(\begin{array}{cc}
1-\mu_{L} d t & \mu_{L} d t \\
\mu_{H} d t & 1-\mu_{H} d t
\end{array}\right)
$$

\section{B. Firms' Optimal Capital and Labor Decisions}

Each project $j$ arrives with project-specific productivity at the long-term mean $u_{j, t}=1$. When a project $j$ arrives, the firms $f$ chooses labor $L_{j}$ and capital $K_{j}$ to maximize NPV:

$$
\begin{aligned}
N P V= & A\left(\epsilon_{f, t}, 1\right) x_{t} K_{j}^{\alpha_{s}} L_{j}^{1-\hat{\alpha}_{s}}+x_{t} z_{t}^{-1} M K_{j}-z_{t}^{-1} x_{t} K_{j} \\
& -\left[v x_{t}\left(B^{f l e x}\right)^{-1}+(1-v) x_{T_{j}}\left(B^{r i g}\right)^{-1}\right] w L_{j}
\end{aligned}
$$

The first order condition for $L_{j}$ gives:

$$
L_{j}^{*}=\left(v x_{t}\left(B^{f l e x}\right)^{-1}+(1-v) x_{T_{j}}\left(B^{r i g}\right)^{-1}\right)^{-\frac{1}{\hat{\alpha}_{s}}} A\left(\epsilon_{f, t}, 1\right)^{\frac{1}{\hat{\alpha}_{s}}} K_{j}^{\frac{\alpha_{s}}{\hat{\alpha}_{s}}}\left(\frac{1}{w}\right)^{\frac{1}{\hat{\alpha}_{s}}} x_{t}^{\frac{1}{\hat{\alpha}_{s}}}\left(1-\hat{\alpha}_{s}\right)^{\frac{1}{\hat{\alpha}_{s}}}
$$

Note that at the project $j^{\prime} s$ arrival at $t=T_{j}, x_{t}$ and $x_{T_{j}}$ cancel out of this formula. Using this expression in the NPV formula (16) and taking the first order condition for $K_{j}$ gives optimal 
investment:

$$
K_{j}^{*}=\left(\frac{\hat{\alpha}_{s}}{\alpha_{s}}\right)^{\frac{\hat{\alpha}_{s}}{\alpha_{s}-\hat{\alpha}_{s}}}\left(z_{t}^{-1}(1-M)\right)^{\frac{\hat{\alpha}_{s}}{\alpha_{s}-\hat{\alpha}_{s}}} A\left(\epsilon_{f, t}, 1\right)^{\frac{-1}{\alpha_{s}-\hat{\alpha}_{s}}} D\left(\hat{\alpha}_{s}, w\right)^{\frac{-\hat{\alpha}_{s}}{\alpha_{s}-\hat{\alpha}_{s}}}
$$

where $D\left(\hat{\alpha}_{s}, w\right)=\left(v\left(B^{f l e x}\right)^{-1}+(1-v)\left(B^{r i g}\right)^{-1}\right)^{\frac{\hat{\alpha}_{s}-1}{\hat{\alpha}_{s}}}\left(\left(\frac{1-\hat{\alpha}_{s}}{w}\right)^{\frac{1-\hat{\alpha}_{s}}{\hat{\alpha}_{s}}}-w\left(\frac{1-\hat{\alpha}_{s}}{w}\right)^{\frac{1}{\hat{\alpha}_{s}}}\right)$.

\section{Valuation of Consumption-Goods Firms}

The time $t$ value of a firm is the sum of the values of all existing projects, i.e., value of assets at place, and the sum of the positive values of projects that are expected to arrive in future, i.e., firm's growth opportunities. The time $t$ value of firm $f^{\prime} s$ existing projects is:

$$
\begin{aligned}
V A P_{f, t} & =\sum_{j \in J_{f}}^{J_{f}} p\left(\epsilon_{f, t}, u_{j, t}, x_{t}, z_{t}, w, K_{j}, L_{j}\right)=\sum_{j \in J_{f}}^{J_{f}} C F I_{j, t}+R S_{j, t}-C F O_{j, t} \\
& =C F I_{f, t}+R S_{f, t}-C F O_{f, t} .
\end{aligned}
$$

The present value of firm $f^{\prime} s$ growth opportunities, $P V G O_{f, t}$, is the sum of the net present values, $N P V_{f, t}$, of all future projects:

$$
N P V_{f, t}=x_{t} A\left(\epsilon_{f, t}, 1\right)^{\frac{-1}{\alpha_{s}-\hat{\alpha}_{s}}}\left(z_{t}^{-1}(1-M)\right)^{\frac{\alpha_{s}}{\alpha_{s}-\hat{\alpha}_{s}}} D\left(\hat{\alpha}_{s}, w\right)^{\frac{-\hat{\alpha}_{s}}{\alpha_{s}-\hat{\alpha}_{s}}}\left[\left(\frac{\hat{\alpha_{s}}}{\alpha_{s}}\right)^{\frac{\alpha_{s}}{\alpha_{s}-\hat{\alpha}_{s}}}-\left(\frac{\hat{\alpha_{s}}}{\alpha_{s}}\right)^{\frac{\hat{\alpha}_{s}}{\alpha_{s}-\hat{\alpha}_{s}}}\right] .
$$

The expression for the value of firm $f^{\prime} s$ growth opportunities can be concisely written as:

$$
P V G O_{f, t}=x_{t} z_{t}^{\frac{\alpha_{s}}{\hat{\alpha}_{s}-\alpha_{s}}} G\left(\epsilon_{f, t}, \lambda_{f, t}, \alpha_{s}, \hat{\alpha}_{s}, w\right)
$$

where $G\left(\epsilon_{f, t}, \lambda_{f, t}, \alpha_{s}, \hat{\alpha}_{s}, w\right)$ is defined in appendix.

The firm $f^{\prime} s$ total value is then:

$$
V_{f, t}=\sum_{j \in J_{f}}^{J_{f}} p\left(\epsilon_{f, t}, u_{j, t}, x_{t}, w, K_{j}, L_{j}\right)+x_{t} z_{t}^{\frac{\alpha_{s}}{\hat{\alpha}_{s}-\alpha_{s}}} G\left(\epsilon_{f, t}, \lambda_{f, t}, \alpha_{s}, \hat{\alpha}_{s}, w\right)
$$

\section{Stock Returns of Consumption-Goods Firms}

The expected excess return on firm $f$ in the consumption-goods sector is:

$$
\frac{1}{d t} \mathbf{E}_{t}\left[R_{f, t}\right]-r_{f}=-\operatorname{cov}\left(\frac{d V_{f, t}}{v_{f, t}}, \frac{d \pi_{t}}{\pi_{t}}\right)
$$

Explicit closed-form expression for the expected excess return can be derived if the expected excess return is calculated as weighted average expected excess return of the particular components of the 
firm value $V_{f, t}$, namely $C F I_{f, t}, C F O_{f, t}, R S_{f, t}$ and $P V G O_{f, t}$. The expected return of the first three components are:

$$
\begin{gathered}
\frac{1}{d t} \mathbf{E}_{t}\left[R_{t}^{C F I}\right]-r_{f}=-\operatorname{cov}\left(\frac{d C F I_{t}}{C F I_{t}}, \frac{d \pi_{t}}{\pi_{t}}\right)=\sigma_{x} \gamma_{x} \\
\frac{1}{d t} \mathbf{E}_{t}\left[R_{t}^{R S}\right]-r_{f}=-\operatorname{cov}\left(\frac{d R S_{t}}{R S_{t}}, \frac{d \pi_{t}}{\pi_{t}}\right)=\sigma_{x} \gamma_{x}-\sigma_{z} \gamma_{z} \\
\frac{1}{d t} \mathbf{E}_{t}\left[R_{t}^{C F O}\right]-r_{f}=-\operatorname{cov}\left(\frac{d C F O_{t}}{C F O_{t}}, \frac{d \pi_{t}}{\pi_{t}}\right)=v \sigma_{x} \gamma_{x}
\end{gathered}
$$

Accordingly, the expected excess return of the firm's value at place $V A P_{f, t}$ is:

$$
\begin{aligned}
\frac{1}{d t} \mathbf{E}_{t}\left[R_{t}^{V A P}\right]-r_{f}= & \left(\frac{1}{d t} \mathbf{E}_{t}\left[R_{t}^{C F I}\right]-r_{f}\right) \frac{C F I_{f, t}}{C F I_{f, t}+R S_{f, t}-C F O_{f, t}} \\
& +\left(\frac{1}{d t} \mathbf{E}_{t}\left[R_{t}^{R S}\right]-r_{f}\right) \frac{R S_{f, t}}{C F I_{f, t}+R S_{f, t}-C F O_{f, t}} \\
& -\left(\frac{1}{d t} \mathbf{E}_{t}\left[R_{t}^{C F O}\right]-r_{f}\right) \frac{C F O_{f, t}}{C F I_{f, t}+R S_{f, t}-C F O_{f, t}} \\
= & \sigma_{x} \gamma_{x} \frac{C F I_{f, t}+R S_{f, t}-v C F O_{f, t}}{V A P_{f, t}}-\sigma_{z} \gamma_{z} \frac{R S_{f, t}}{V A P}
\end{aligned}
$$

It is obvious from the formula (27) that expected return of the value of assets at place depends on the exposure to both underlying risks $x_{t}$ and $z_{t}$. This is different from the KP model, where the expected return of assets in place depends only on its exposure to the aggregate productivity shock $x_{t}$. The first term in formula (27) is a levered claim on the aggregate productivity shock $x_{t}$. The leverage arises from the rigidity of the wage. While the output fluctuates with the aggregate productivity shock $x_{t}$, the fraction $(1-v)$ of the labor force has a constant wage and hence results in constant labor cost, which is reflected in operating leverage. The operating leverage is determined by the parameter $v$. If $v=1$, the $C F I_{f, t}+R S_{f, t}-v C F O_{f, t}=V A P_{f, t}$ and the firm is unlevered. In contrast $v=0$ corresponds to the maximum possible leverage where $C F I_{f, t}+R S_{f, t}-v C F O_{f, t}=$ $C F I_{f, t}+R S_{f, t}>V A P_{f, t}$. The second term in the formula reflects the exposure of assets at place to the investment shocks $z_{t}$. This exposure arises from the capital re-sale when a project expires.

The expected excess return on the growth option is:

$$
\frac{1}{d t} \mathbf{E}_{t}\left[R_{f, t}^{P V G O}\right]-r_{f}=-\operatorname{cov}\left(\frac{d P V G O_{f, t}}{P V G O_{f, t}}, \frac{d \pi_{t}}{\pi_{t}}\right)=\sigma_{x} \gamma_{x}+\frac{\alpha_{s}}{\hat{\alpha}_{s}-\alpha_{s}} \sigma_{z} \gamma_{z}
$$

Accordingly, the expected excess return on the whole firm is a weighted average of the expected 
return on the firm $f^{\prime} s$ assets at place, $V A P$, and growth opportunities, $P V G O$ :

$$
\begin{aligned}
\frac{1}{d t} \mathbf{E}_{t}\left[R_{f, t}\right]-r & =\sigma_{x} \gamma_{x} \frac{V_{f, t}+(1-v) C F O_{f, t}}{V_{f, t}}+\sigma_{z} \gamma_{z}\left(\frac{\frac{\alpha_{s}}{\hat{\alpha}_{s}-\alpha_{s}} P V G O_{f, t}-R S_{f, t}}{V_{f, t}}\right) \\
& =\sigma_{x} \gamma_{x} \beta_{f, t}^{x}+\sigma_{z} \gamma_{z} \beta_{f, t} z .
\end{aligned}
$$

It is also useful to derive an expression for a firm's exposure to the investment shock $z_{t}$ :

$$
\beta_{f, t}^{z}=\frac{\delta \ln V_{f, t}}{\delta \ln z_{t}}=\frac{\frac{\alpha_{s}}{\hat{\alpha}_{s}-\alpha_{s}} P V G O_{f, t}-R S_{f, t}}{V_{f, t}} .
$$

Finding a reliable empirical counterpart for firm's true exposure to the investment shocks, $\beta_{f, t}^{z}$, is important for measuring the effects of investment shocks on firms. Below, I derive the formula for the empirical proxy of the investment shock suggested by previous literature, the IMC portfolio, which allows for the IMC portfolio to be exposed also to the aggregate productivity shocks $x_{t}$. This allows to discuss how reliably a firm's exposure to such IMC portfolio, $\beta_{f, t}^{I M C}$ reflects the firm's growth opportunities, $P V G O_{f, t}$, and its true exposure to the investment shock, $\beta_{f, t}^{z}$. At this point, it is obvious that even simply approximating firm's exposure to the investment shock by firm's growth opportunities might be problematic for two reasons. First, $\beta_{f, t}^{z}$ depends not only on firm's growth opportunities, $P V G O_{f, t}$, but also on the potential capital re-sale, $R S_{f, t}$. Second, the growth opportunities are multiplied by $\frac{\alpha_{s}}{\hat{\alpha}_{s}-\alpha_{s}}$, which captures a firm's capital intensity and varies strongly in the cross section of firms.

\section{E. Valuation of the Investment-Goods Firm}

Investment firm is modeled in a simplified form to get an appropriate counter-part for consumptiongoods firms. I assume that the investment-goods firm produces exactly the capital demanded by the consumption-goods firms less the capital that is re-sold among the consumption-goods firms by themselves. This assumption would correspond to a market clearing condition on the market for capital in a general equilibrium setting.

The total expected demand for capital from sector s is $\bar{\lambda} \int_{F_{s}} K_{f, t}^{*} d f$, where $K_{f, t}^{*}$ is the optimal capital for newly arrived projects of firm $f$ as described above. The expected capital re-sold by the consumption-goods firms in sector $s$ consists of two parts. First, the already existing capital is $\int_{f_{s}} K_{f, t} d f=K_{s, t}$ and has a probability to be re-sold in future. Second, the capital which will be demanded in future for newly arrived project will be re-sold when these projects expire later. The profit of the investment-goods firm is the total amount of the capital sold by the investment firm (i.e., total demanded capital less the capital re-sold among the consumption-goods firms) multiplied with the profit margin $\phi$.

The total expected amount of capital demanded by consumption-goods firms in each sector $s$ 
at each point in time is:

$$
\bar{\lambda} \int_{F_{s}} K_{f, t}^{*} d f=\bar{\lambda}\left(\frac{\hat{\alpha}_{s}}{\alpha_{s}}\right)^{\frac{\hat{\alpha}_{s}}{\alpha_{s}-\hat{\alpha}_{s}}}\left(z_{t}^{-1}(1-M)\right)^{\frac{\hat{\alpha}_{s}}{\alpha_{s}-\hat{\alpha}_{s}}} D\left(\hat{\alpha}_{s}, w\right)^{\frac{\hat{\alpha}_{s}}{\hat{\alpha}_{s}-\alpha_{s}}} \int_{F_{s}} A\left(\epsilon_{f, t}, 1\right)^{\frac{1}{\hat{\alpha}_{s}-\alpha_{s}}} d f .
$$

The present value of the total capital demand is sector $\mathrm{s}$ is:

$$
\begin{aligned}
P D V_{s, t}= & \mathbf{E}_{t}\left[\int_{t}^{\infty} x_{s} z_{s}^{-1} \frac{\pi_{s}}{\pi_{t}} \bar{\lambda}_{s}\left(\frac{\hat{\alpha}_{s}}{\alpha_{s}}\right)^{\frac{\hat{\alpha}_{s}}{\alpha_{s}-\hat{\alpha}_{s}}}\left(z_{s}^{-1}(1-M)\right)^{\frac{\hat{\alpha}_{s}}{\alpha_{s}-\hat{\alpha}_{s}}} D\left(\hat{\alpha}_{s}, w\right)^{\frac{\hat{\alpha}_{s}}{\hat{\alpha}_{s}-\alpha_{s}}}\right. \\
& \left.\left(\int_{F_{s}} A(\epsilon f, t, 1)^{\frac{1}{\hat{\alpha}_{s}-\alpha_{s}}} d f\right) d s\right] .
\end{aligned}
$$

The present value of the re-sale of the existing capital is:

$$
N D V P_{s, t}=\mathbf{E}_{t}\left[\int_{t}^{\infty} \delta e^{-\delta(s-t)} \frac{\pi_{s}}{\pi_{t}} x_{s} z_{s}^{-1}\left(\int_{F_{s}} K_{f, t} d f\right) d s\right]=x_{t} z_{t}^{-1} M K_{s, t} .
$$

The present value of the re-sale of the capital of projects that are expected to arrive in future is:

$$
N D V F_{s, t}=\frac{1}{Q} \bar{\lambda} M x_{t} z_{t}^{-1}\left(\int_{F_{s}} K_{f, t}^{*} d f\right)
$$

, where $Q=r-\mu_{x}+\mu_{z}-\sigma_{z}^{2}+\sigma_{x} \gamma_{x}-\sigma_{z} \gamma_{z}$. The present value of the demand which will be supplied by the investment firm is:

$$
\begin{aligned}
I D_{t} & =\sum_{s \in\{L, H\}} P D V_{s, t}-N D V P_{s, t}-N D V F_{s, t} \\
& =x_{t} z_{t}^{\frac{\alpha_{L}}{\hat{\alpha}_{L}-\alpha_{L}}} \sum_{s \in\{L, H\}} \Gamma_{s}(1-M)^{\frac{\hat{\alpha}_{s}}{\alpha_{s}-\bar{\alpha}_{s}}}-x_{t} z_{t}^{-1}\left(\frac{1}{Q} \bar{\lambda}_{s} M\left(\int_{F_{s}} K_{f, t}^{*} d f\right)-M K_{s, t}\right) .
\end{aligned}
$$

The value of the investment-goods firm is then:

$$
V_{t}^{I}=\phi I D_{t}
$$




\section{F. Expected Excess Return of the Investment-Goods Firm}

The expected excess return of the investment-goods firm can be calculated as the weighted average expected excess return of the individual demand components as:

$$
\begin{aligned}
\frac{1}{d t} \mathbf{E}_{t}\left[R_{t}^{I}\right]-r= & \sum_{s \in\{L, H\}}\left(\frac{1}{d t} \mathbf{E}_{t}\left[R_{t}^{P D V_{s}}\right]-r\right) \frac{\phi P D V_{s, t}}{V_{t}^{I}} \\
& -\sum_{s \in\{L, H\}}\left(\frac{1}{d t} \mathbf{E}_{t}\left[R_{t}^{N D V P_{s}}\right]-r\right) \frac{\phi N D V P_{s, t}}{V_{t}^{I}} \\
& -\sum_{s \in\{L, H\}}\left(\frac{1}{d t} \mathbf{E}_{t}\left[R_{t}^{N D V F_{s}}\right]-r\right) \frac{\phi N D V F_{s, t}}{V_{t}^{I}} .
\end{aligned}
$$

Expected excess return of the positive demand component $\left(P D V_{s, t}\right)$ is:

$$
\frac{1}{d t} \mathbf{E}_{t}\left[R_{t}^{P D V_{s}}\right]-r=\sigma_{x} \gamma_{x}+\frac{\alpha_{s}}{\hat{\alpha}_{s}-\alpha_{s}} \sigma_{z} \gamma_{z}
$$

Expected excess return of the negative demand components $\left(N D V P_{s, t}\right.$ and $\left.N D V F_{s, t}\right)$ is:

$$
\frac{1}{d t} \mathbf{E}_{t}\left[R_{t}^{N D V P_{s}}\right]-r=\sigma_{x} \gamma_{x}-\sigma_{z} \gamma_{z}
$$

and

$$
\frac{1}{d t} \mathbf{E}_{t}\left[R_{t}^{N D V F_{s}}\right]-r=\sigma_{x} \gamma_{x}+\frac{\alpha_{s}}{\hat{\alpha}_{s}-\alpha_{s}} \sigma_{z} \gamma_{z}
$$

The expected excess return of the investment-goods firm is:

$$
\frac{1}{d t} \mathbf{E}_{t}\left[R_{t}^{I}\right]-r=\sigma_{x} \gamma_{x}+\sigma_{z} \gamma_{z} \sum_{s \in\{L, H\}} \frac{\frac{\alpha_{s}}{\hat{\alpha}_{s}-\alpha_{s}}\left(P D V_{s, t}-N D V F_{s, t}\right)+N D V P_{s, t}}{V_{t}^{I}} .
$$

The second term in this formula shows the exposure of the investment-goods firm to the investment shock $z_{t}$. In this setting, an investment-goods firm will a positive exposure to the investment shock if $\sum_{s \in\{L, H\}} \frac{\alpha_{s}}{\hat{\alpha}_{s}-\alpha_{s}}\left(P D V_{s, t}-N D V F_{s, t}\right)+N D V P_{s, t}>0$, which is satisfied in this model. The first term captures the exposure fo the firm to the aggregate productivity shock $x_{t}$. Since I do not explicitly model the capital or operating structure of the investment-goods firms, the first term is an unlevered claim on the underlying aggregate shock $x_{t}$. A levered exposure of the investmentgoods firm to the aggregate shock $x_{t}$ would, however, affect the exposure of the IMC portfolio to this shock and I introduce this to the model directly when I construct the IMC portfolio below.

\section{G. Expected Excess Return on the IMC Portfolio}

The closed-form expressions for the expected returns of the consumption-goods and investmentgoods firms allow to express also the expected returns of the IMC portfolio, i.e., a long-short 
portfolio with a long position in the investment-goods firm and a short position in the consumptiongoods firms. The expected excess return on each of the cross-section of consumption-goods firms is the value-weighted average of expected returns across the firms in each consumption-goods sector $s:$

$$
\begin{aligned}
\frac{1}{d t} \mathbf{E}_{t}\left[R_{t}^{s, C}\right]-r & =\int_{F_{s}}\left(\frac{1}{d t} \mathbf{E}_{t}\left[R_{f, t}\right]-r\right) \frac{V_{f, t}}{\int_{F_{s}} V_{v, t} d v} d f \\
& =\sigma_{x} \gamma_{x} \frac{\int_{F_{s}} 1+(1-v) C F O_{f, t} d f}{\int_{F_{s}} V_{f, t} d f}+\sigma_{z} \gamma_{z} \frac{\int_{F_{s}} \frac{\alpha_{s}}{\hat{\alpha}_{s}-\alpha_{s}} P V G O_{f, t}-R S_{f, t} d f}{\int_{F_{s}} V_{f, t} d f} .
\end{aligned}
$$

To simplify the notation, I define $V_{t}^{C}=\sum_{s \in\{L, H\}} \int_{F_{s}} V_{f, t} d f$, which denotes the total value of all consumption-goods firms in both, the capital-intensive and labor-intensive sector. The expected excess return of the whole consumption-goods sector can be written on as:

$$
\begin{aligned}
\frac{1}{d t} \mathbf{E}_{t}\left[R_{t}^{C}\right]-r= & \sigma_{x} \gamma_{x} \sum_{s \in\{L, H\}} \frac{\int_{F_{s}}\left(1+(1-v) C F O_{f, t}\right) d f}{V_{t}^{C}} \\
& +\sigma_{z} \gamma_{z} \sum_{s \in\{L, H\}} \frac{\int_{F_{s}} \frac{\alpha_{L}}{\hat{\alpha}_{L}-\alpha_{L}} P V G O_{f, t}-R S_{f, t} d f}{V_{t}^{C}} .
\end{aligned}
$$

The expected excess return of the IMC portfolio can be calculated by subtracting the expected return of the consumption-goods sector from the expected return of the investment-goods sector. If both sectors have exactly the same exposure to the aggregate shock $x_{t}$, these exposures will cancel each other and the resulting IMC portfolio will span purely the dimension of the investment shock $z_{t}$. In reality both, the investment-goods and consumption-goods firms differ in their exposure to aggregate risk factors. Table 1 shows that the empirical IMC portfolio is positively correlated with the market and the $S M B$ factors, both of which carry a positive return premium. In order to allow the theoretical IMC portfolio to correlate not only with the negatively priced investment shocks $z_{t}$, but also with positively priced shocks, I introduce the parameter $L D I F F$. In the narrow sense, this parameter expresses the difference in the operating leverage between consumption-goods and investment-goods firms. More broadly, it can be thought of as any difference between investmentgoods and consumption-goods firms which results in a different exposure to the positively priced aggregate risk factor $x_{t}{ }^{6}$ Using this modeling shortcut, the expected return of the IMC portfolio

\footnotetext{
${ }^{6}$ It is possible to model the operating (or other) leverage of the investment-goods firm in the specification of the firm's cash flow in formula 35. Since the return of the IMC portfolio and not the return of the investment-goods firm itself is of immediate interest, the above specification provides an equivalent modeling solution.
} 
can be written as:

$$
\begin{aligned}
\frac{1}{d t} \mathbf{E}_{t}\left[R_{t}^{I}-R_{t}^{C}\right]= & -\sigma_{x} \gamma_{x} \sum_{s \in\{L, H\}} \frac{\int_{F_{s}}(1-v) C F O_{f, t} d f}{V_{t}^{C}} L D I F F \\
& +\sigma_{z} \gamma_{z} \sum_{s \in\{L, H\}} \frac{\frac{\alpha_{s}}{\hat{\alpha}_{s}-\alpha_{s}}\left(P D V_{s, t}-N D V F_{s, t}\right)+N D V P_{s, t}}{V_{t}^{I}} \\
& -\sigma_{z} \gamma_{z} \sum_{s \in\{L, H\}} \frac{\int_{F_{s}} \frac{\alpha_{s}}{\hat{\alpha}_{s}-\alpha_{s}} P V G O_{f, t}-R S_{f, t} d f}{V_{t}^{C}} .
\end{aligned}
$$

The realized return of the IMC portfolio is the expected return and the corresponding stochastic part. For the sake of simplicity, I define $C F O_{t}=\sum_{s \in\{L, H\}} \frac{\int_{F_{s}}(1-v) C F O_{f, t} d f}{V_{t}^{C}}$,

$I N V_{t}=\sum_{s \in\{L, H\}} \frac{\frac{\alpha_{s}}{\hat{\alpha}_{s}-\alpha_{s}}\left(P D V_{s, t}-N D V F_{s, t}\right)+N D V P_{s, t}}{V_{t}^{I}}$ and

$P V G O R S_{t}=\sum_{s \in\{L, H\}} \frac{\int_{F_{s}} \frac{\alpha_{s}}{\hat{\alpha}_{s}-\alpha_{s}} P V G O_{f, t}-R S_{f, t} d f}{V_{t}^{C}}$. The realized return of the IMC portfolio can be written as:

$$
\begin{aligned}
R_{t}^{I}-R_{t}^{C}= & -C F O_{t} \times \operatorname{LDIFF}\left(\sigma_{x} \gamma_{x} d t+\sigma_{x} d B_{x_{t}}\right) \\
& +\left(I N V_{t}-P \operatorname{PGOR} S_{t}\right)\left(\sigma_{z} \gamma_{z} d t+\sigma_{z} d B_{z_{t}}\right)
\end{aligned}
$$

The exposure of the IMC portfolio to the aggregate shock $x_{t}$ depends on the similarity of the investment and consumption firms, $C F O_{t} \times L D I F F$. The exposure to the investment shocks $z_{t}$, depends on the relative value of growth opportunities to total firm value of the consumption firm as well as on how much of the demanded capital will be supplied by the investment firm vs. by re-sale, $I N V_{t}-P V G O R S_{t}$.

\section{Empirical Implications}

\section{A. $\quad \beta_{f, t}^{I M C}$ as a Measure of Firm's Exposure to the Investment Shocks}

In this section I analyze the IMC portfolio as an empirical proxy for investment shock. The purpose is to understand how well the IMC portfolio can capture firm's exposure to the investment shock. In the ideal case when the IMC portfolio is exposed only to investment shock $z_{t}$, firm's exposure to the IMC portfolio will map one-to-one to firm's exposure to investment shock $z_{t}$. However, in reality the IMC portfolio correlates strongly with the market and $S M B$ factors, whose theoretical counterpart is the aggregate shock $x_{t}$. The closed-form expression of firm's exposure to the IMC portfolio, $\beta_{f, t}^{I M C}$, allows to analyze the pitfalls of estimating firm's exposure to investment shocks from its exposure to the IMC portfolio and, at least partially, reconcile the empirical observations. 
Firm $f^{\prime} s$ exposure to the IMC portfolio is:

$$
\begin{aligned}
\beta_{f, t}^{I M C}= & \frac{\operatorname{cov}\left(R_{f, t}, R_{t}^{I M C}\right)}{\operatorname{var}\left(R_{t}^{I M C}\right)} \\
= & -\frac{\sigma_{x}^{2}\left(\frac{V_{f, t}+(1-v) C F O_{f, t}}{V_{f, t}}\right) C F O_{t} \times L D I F F}{\sigma_{x}^{2}\left(C F O_{t} \times L D I F F\right)^{2}+\sigma_{z}^{2}\left(I N V_{t}-P V G O R S_{t}\right)^{2}} \\
& +\frac{\sigma_{z}^{2}\left(\frac{\frac{\alpha_{s}}{\hat{\alpha}_{s}-\alpha_{s}} P V G O_{f, t}-R S_{f, t}}{V_{f, t}}\right)\left(I N V_{t}-P V G O R S_{t}\right)}{\sigma_{x}^{2}\left(C F O_{t} \times L D I F F\right)^{2}+\sigma_{z}^{2}\left(I N V_{t}-P V G O R S_{t}\right)^{2}} .
\end{aligned}
$$

Firm $f^{\prime} s$ exposure to the IMC portfolio depends on the particular components of firm $f^{\prime} s$ total value as well as on the IMC portfolio's exposure to the shocks $x_{t}$ and $z_{t}$. Motivated by the empirical observation of a positive correlation between the IMC portfolio and the market returns (and the SMB factor), I assume $L D I F F<0$, which delivers the corresponding correlation between the aggregate shock $x_{t}$ and the IMC portfolio. Further, I assume $I N V_{t}-P V G O R S_{t}>0$ which means that investment-goods firms are more exposed to IST shock than consumption-goods firms, which is the main motivation for using this portfolio as an empirical proxy for the IST shock as described in Papanikolaou (2011).

Table VI summarizes how the particular value components affect firm's exposure to the shocks $x_{t}$ and $z_{t}$ as well as its exposure to the IMC portfolio. Firm's operating leverage arising from $(1-v) \frac{C F O_{f, t}}{V_{f, t}}$ increases firm's exposure to aggregate shock $x_{t}$ so that also $\beta_{f, t}^{I M C}$ increases. The fraction of firms value arising from growth opportunities $\frac{P V G O_{f, t}}{V_{f, t}}$ increases firms exposure to the investment shock and to the IMC portfolio by a factor $\frac{\alpha_{s}}{\hat{\alpha}_{s}-\alpha_{s}}$. This factor depends on a firm's capital intensity and hence will be different for capital-intensive and labor-intensive firms. The value of potential re-sale $R S_{f, t}$ is negatively correlated with the shock $z_{t}$ and hence it decreases firm's exposure to both, the investment shock and the IMC portfolio.

This analysis shows that firm's $\beta_{f, t}^{I M C}$ is not a precise measure of firm's exposure to the IST shocks and the quality of this measure depends both, the components of firm's total value and the exposure of the IMC portfolio to the aggregate shock $x_{t}$. For instance, a capital-intensive firm with large growth opportunities relative to existing assets will have a high exposure to the IMC portfolio due to its exposure to the investment shock, $z_{t}$. In contrast, highly levered labor-intensive firm will have high exposure to the IMC portfolio due to its exposure to the aggregate shock $x_{t}$. accordingly, similar magnitudes of the $\beta_{f, t}^{I M C}$ may have a different meaning in terms of describing the exposure to the underlying shocks for capital-intensive and labor-intensive firms.

I test this empirical prediction in table VII. I use market-to-book ratio as an approximation of a firm's growth opportunities and the ratio of a firm's capital (property, plant and equipment) to market capitalization as an approximation for of firm's potential capital resale. Operating leverage is measure as a ratio of cost of goods sold and selling, general and administrative expenses to firm's market capitalization. The first column shows that $\beta_{f, t}^{I M C}$ is positively related to firm's growth opportunities as well as to firm's operating leverage as predicted by the model. Contrary to the 
prediction of the model, firm's exposure to the IMC portfolio is also positively related to firm's potential capital resale. Potential reason for this result is that the ratio of firm's capital to market capitalization is a poor measure of firm's capital resale.

Second and third column show the estimates for capital-intensive and labor intensive firms separately. Consistent with the prediction of formula (46), the link between firm's growth opportunities and its exposure to the IMC portfolio is much stronger among capital-intensive firms, but almost absent among labor-intensive firms. These two columns also show that link between firm's operating leverage and the exposure to the IMC portfolio is significant for labor intensive firms, but of lower magnitude and insignificant for capital-intensive firms. I repeat the estimation with an alternative measure of operating leverage that accounts only for selling, general and administrative expenses. The motivation for this alternation is that these costs are likely to be more rigid than the costs of goods sold and can better approximate firm's operating leverage. The last two columns show that results based on this measure are similar.

The model also allows to derive cross-sectional asset pricing implications of shock, growth opportunities and capital-intensity. The formula (29) shows that in this model, firm's expected return is a linear function of firms exposure to the aggregate shock $x_{t}$ and the exposure to the investment shock $z_{t}$. The expression for a firm's $\beta_{f, t}^{z}$ in formula 30 shows that firm's exposure to the investment shock depends on firm's growth opportunities and firm's capital intensity (and firm's potential capital resale that does not seem to b empirically relevant). According to this model, we should expect a linear relationship between firm's expected returns and $\beta_{f, t} z$. Moreover, under the assumption that the growth opportunities span approximately the same range among both, capital-intensive and labor-intensive firms (see the $10^{\text {th }}$ and $90^{\text {th }}$ percentiles of the book-to-market ratio in table IV), portfolios of capital-intensive firms sorted by $\beta_{f, t}^{z}$ should exhibit larger differences in expected returns and in the exposure to the investment shock than the portfolios consisting of labor-intensive firms.

While the results in $V$ seem to support the prediction of stronger return differences among capital-intensive firms, they also show almost identical patterns in the exposure to the IMC portfolio for both types of firms. Comparing the expressions for $\beta_{f, t}^{I M C}$ and $\beta_{f, t}^{z}$ in formulas 46 and (30) suggests that this result can arise due to a potential bias in $\beta_{f, t}^{I M C}$ as a measure of $\beta_{f, t}^{z}$.

In table VIII, I repeat the analysis from table $\mathrm{V}$ but I sort the stocks based on $\beta_{f, t}^{I M C+\text { controls }}$ that is estimated from multivariate regression of this form:

$$
R_{f, t}-R^{\text {riskfree }}=\alpha_{f, t}+\beta_{f, t}^{I M C+\text { controls }} \times R_{t}^{I M C}+\beta_{f, t}^{\text {market }} \times R_{t}^{\text {market }}+\beta_{f, t}^{S M B} \times R_{t}^{S M B}+\epsilon_{f, t} .
$$

I include the returns on market and the $S M B$ factors, so that $\beta^{I M C+\text { controls }}$ is relatively unbiased by the exposure to these two factors and hence may come closer to the theoretical ideal of $\beta_{f, t}^{z}$.

Panels A, B and C confirm the results for average excess and abnormal returns from table V. Capital-intensive firms exhibit a slightly decreasing pattern of average excess returns and a 
strong decreasing pattern of $\alpha$ across the portfolios, while labor-intensive firms do not. Panel D, however shows that also the exposure to the IMC portfolio differ. While the exposure of the capitalintensive long-short portfolio, HL, has an exposure to the IMC portfolio of 0.97, the labor-intensive counterpart has exposure of only 0.64. Panel E shows the exposures to the IMC portfolio and the loadings on the market return and the $S M B$ factor estimated from a multivariate regression that controls for these two factors. These results also show large differences in the portfolios' exposures to the IMC portfolio between capital-intensive and labor-intensive firms. Although it is not clear whether the difference in $\alpha$ between the capital-intensive and labor-intensive long-short portfolios can be fully explained by their different exposure to the IMC portfolio, the results support the intuition of the theoretical model.

It is worthwhile mentioning that also the relatively small exposure of the labor-intensive longshort portfolio to the IMC portfolio is associated with much stronger (negative) exposure to the HML factor. This also seems to be consistent with the theoretical prediction of the model that large growth opportunities of labor-intensive firms will be associated with only moderate exposure to the investment shock. At the same time, relatively low growth opportunities of capital-intensive firms will be linked to large exposure to the investment shock.

\section{Model Calibration and Simulation}

I calibrate the model with most of the parameters having same or similar values as in Kogan and Papanikolaou (2014) to allow a comparison with this benchmark model. These parameters were originally selected to match moments of aggregate dividend and investment growth, asset returns, accounting ratios, the IMC portfolio properties and capital intensity of firms.7 The additional parameters in my extended model, $\alpha_{L}, \alpha_{H}, \hat{\alpha}_{L}, \hat{\alpha}_{H}, w, v$, and $L D I F F$, govern the capital-labor ratio of capital- and labor-intensive firms, wage rigidity, operating leverage, the exposure of firms' growth opportunities to investment shock and correlation of the IMC portfolio returns with aggregate market excess returns, aggregate shock $x_{t}$ and investment shock $z_{t}$. I select these parameters to approximately match the relative capital-labor ratio, i.e., capital-labor ratio of capital-intensive firms relative to the same ratio of labor-intensive firms, the correlation between the IMC portfolio returns and the excess market return, and the different patterns in of abnormal returns between capital-intensive and labor-intensive firms. The parameters are provided in table IX.

The goal of this exercise is to provide a quantitative result in support of the asset pricing implication of the model and show that capital-intensity matters for $\beta_{f, t}^{I M C}$ sorted stocks as found in the data. At the same time, it is important to note that not all moments can be matched precisely as the model abstracts from other potential factors such as competition, or capital utilization, which can affect the investment behavior of firms and their riskiness. I simulate a cross-section of consumption-goods firms and the necessary counter-part of investment-good firm. The crosssection of consumption-goods firms consists of two sub-samples, namely capital-intensive and labor-

\footnotetext{
${ }^{7} \mathrm{I}$ use a lower parameter for the growth of the investment shock, $\mu_{z}=0.001$ instead of 0.005 , as it helps the simulated relative capital-labor ratio, and some return properties come closer to their empirical counterparts.
} 
intensive firms. Each sub-sample consists of 300 firms. I simulate the model 100 times for 100 years and in each simulation I use only the second half (year 51-100) for estimating the moments. I report the median of the moments across individual simulations. The cross-sectional distribution of firm's project arrival rates $\lambda_{f}=\mathbf{E}\left[\lambda_{f, t}\right]$ is given as:

$$
\lambda_{f}=\mu_{\lambda} \delta-\sigma_{\lambda} \delta \log \left(X_{f}\right)
$$

, where $X_{f} \sim N(0,1)$.

Table $\mathrm{X}$ shows the moments from the simulated data from my extended model, the Kogan and Papanikolaou (2014) model (indicated by KP model) and the empirical counterparts. Most of the moments from the extended model are relatively close their empirical or KP counterparts. The biggest differences are for investment growth and investment rate. This is caused by the fact that the extended model is based on a Cobb-Douglas production function with capital and labor. Investment in this model is driven, to large extent, by investment shocks $z_{t}$ that affect directly capital but not labor. I calibrate the model so that the correlation between the IMC portfolio and aggregate market return is somewhat higher than observed in the data. The return of the empirical IMC portfolio correlates not only with return of the market portfolio, but also with the SMB factor. Since the model does not include the SMB factor, a higher correlation with market return can, to some extent, compensate for the missing factor and help match the cross-sectional patterns of portfolio returns. The higher correlation between the IMC portfolio and market return can be achieved by larger differences in operating leverage between consumption-goods and investmentgoods firms, $L D I F F$. Higher magnitude of this parameter then results also in higher volatility of the IMC portfolio return than observed in the data.

Table XI reports the properties of the portfolio returns of firms sorted by their exposure to the IMC portfolio, $\beta^{I M C}$, for capital-intensive and labor-intensive firms simulated in my extended model. It is apparent that the average excess returns of all labor-intensive portfolios are higher than their counterparts for capital-intensive returns. Although we can see in the table $(\mathrm{V})$ that the average excess returns of labor-intensive portfolios are somewhat higher than for capital-intensive portfolios, the differences are not as high as those in simulated data. This discrepancy is due to labor-intensive firms having in the model, on average, a higher exposure to positively priced aggregate risk and only a limited exposure to negatively priced investment shock, which is apparent when individual capital- and labor-intensive portfolios are compared.

Apart from this, the simulated returns show two important patterns. First, sorting capitalintensive firms by the exposure to the IMC portfolio generates much higher $\alpha$ than the same sorting among labor-intensive firms. This is consistent with the observed patterns in the data. Second, the differences in firms' true exposure to the investment shock, $\beta^{z}$, are much bigger among capital-intensive firms. This seems to be consistent with the pattern in $\beta^{I M C}$ in panel $\mathrm{E}$ of table VIII. One has to, however, acknowledge that observing $\beta^{z}$ is challenging in the data and hence the comparison with $\beta I M C$ even if it controls for other factors has to be taken cautiously. 


\section{Conclusion}

In this paper, I exploit the intuition that in a model with a Cobb-Douglas production function and vintage capital, positive investment shocks, i.e., shocks to the formation of new capital, are expected to benefit prominently capital-intensive firms with large growth opportunities. I extend the Kogan and Papanikolaou (2014) model by introducing labor with partially rigid wage as a production factor, which leads to firms' operating leverage. This extended model shows that firm's capital intensity can affect both, the exposure of firm's growth opportunities to the investment shocks and the measurement of firm's exposure to these shocks by its exposure to an IMC portfolio which correlates also with other factors. Differentiating between capital-intensive and labor intensive firms provides some empirical support for the implications of the model. Sorting firms by their exposure to the IMC portfolio in these two sub-samples suggests that capital-intensive growth opportunities are more exposed to investment shocks than their labor-intensive counterparts. The limitation of this framework is that it abstracts from the possibility of capital-labor substitution, which would allow investment shocks to affect also labor-intensive firms regardless of their growth opportunities. 


\section{Derivation of Formulas}

Present value of growth opportunities:

$$
\begin{aligned}
P V G O_{f, t}= & \mathbf{E}_{t}\left[\int_{t}^{\infty} \frac{\pi_{s}}{\pi_{t}} x_{s}\left(z_{s}^{-1}(1-M)\right)^{\frac{\alpha_{s}}{\alpha_{s}-\hat{\alpha}_{s}}} A\left(\epsilon_{f, t}, 1\right)^{\frac{-1}{\alpha_{s}-\hat{\alpha}_{s}}}\right. \\
& \left.\times D\left(\hat{\alpha}_{s}, w\right)^{\frac{-\hat{\alpha}_{s}}{\alpha_{s}-\hat{\alpha}_{s}}}\left[\left(\frac{\hat{\alpha_{s}}}{\alpha_{s}}\right)^{\frac{\alpha_{s}}{\alpha_{s}-\hat{\alpha}_{s}}}-\left(\frac{\hat{\alpha_{s}}}{\alpha_{s}}\right)^{\frac{\hat{\alpha}_{s}}{\alpha_{s}-\hat{\alpha}_{s}}}\right] \lambda_{f, s} d s\right] \\
= & x_{t} z_{t}^{\frac{\alpha_{s}}{\hat{\alpha}_{s}-\alpha_{s}}} C\left(\alpha_{s}, \hat{\alpha}_{s}, w\right) \mathbf{E}_{t}\left[\int_{t}^{\infty} e^{-\rho_{s}(s-t)} \lambda_{f, s} A\left(\epsilon_{f, s}, 1\right)^{\frac{1}{\hat{\alpha}_{s}-\alpha_{s}}} d s\right] \\
= & x_{t} z_{t}^{\frac{\alpha_{s}}{\alpha_{s}-\alpha_{s}}} G\left(\epsilon_{f, t}, \lambda_{f, t}, \alpha_{s}, \hat{\alpha}_{s}, w\right)
\end{aligned}
$$

, where $\rho_{s}=r+\gamma_{x} \sigma_{x}-\mu_{x}-\frac{\alpha_{s}}{\hat{\alpha}_{s}-\alpha_{s}}\left(\mu_{z}-\gamma_{z} \sigma_{z}-\frac{1}{2} \sigma_{z}^{2}\right)-\frac{1}{2}\left(\frac{\alpha_{s}}{\hat{\alpha}_{s}-\alpha_{s}}\right)^{2} \sigma_{z}^{2}$

and $C\left(\alpha_{s}, \hat{\alpha}_{s}, w\right)=D\left(\hat{\alpha}_{s}, w\right)^{\frac{\hat{\alpha}_{s}}{\hat{\alpha}_{s}-\alpha_{s}}}(1-M)^{\frac{\alpha_{s}}{\alpha_{s}-\hat{\alpha}_{s}}}\left[\left(\frac{\hat{\alpha}_{s}}{\alpha_{s}}\right)^{\frac{\alpha_{s}}{\alpha_{s}-\hat{\alpha}_{s}}}-\left(\frac{\hat{\alpha}_{s}}{\alpha_{s}}\right)^{\frac{\hat{\alpha}_{s}}{\alpha_{s}-\hat{\alpha}_{s}}}\right]$.

$$
\begin{aligned}
G\left(\epsilon_{f, t}, \lambda_{f, t}, \alpha_{s}, \hat{\alpha}_{s}, w\right) & =C \mathbf{E}_{t}\left[\int_{t}^{\infty} e^{\rho(s-t)} \lambda_{f, s} A\left(\epsilon_{f, t}\right)^{\frac{\alpha_{s}}{\hat{\alpha}_{s}-\alpha_{s}}} d s\right] \\
& = \begin{cases}\lambda_{f}\left(G_{1}\left(\epsilon_{f, t}\right)+\frac{\mu_{L}}{\mu_{L}+\mu_{H}}\left(\lambda_{H}-\lambda_{L}\right) G_{2}\left(\epsilon_{f, t}\right)\right), & \tilde{\lambda}_{f, t}=\lambda_{H} \\
\lambda_{f}\left(G_{1}\left(\epsilon_{f, t}\right)-\frac{\mu_{H}}{\mu_{L}+\mu_{H}}\left(\lambda_{H}-\lambda_{L}\right) G_{2}\left(\epsilon_{f, t}\right)\right) & , \tilde{\lambda}_{f, t}=\lambda_{L}\end{cases}
\end{aligned}
$$

, where $G_{1}$ and $G_{2}$ are defined as:

$$
\begin{aligned}
& G_{1}\left(\epsilon_{f, t}\right)=X \mathbf{E}_{t}\left[\int_{t}^{\infty} e^{-\rho(s-t)} A\left(\epsilon_{f, s}\right)^{\frac{\alpha_{s}}{\hat{\alpha}_{s}-\alpha}} d s\right] \\
& G_{2}\left(\epsilon_{f, t}\right)=X \mathbf{E}_{t}\left[\int_{t}^{\infty} e^{-\left(\rho+\mu_{L}+\mu_{H}\right)(s-t)} A\left(\epsilon_{f, s}\right)^{\frac{\alpha_{s}}{\alpha_{s}-\alpha}} d s\right]
\end{aligned}
$$

and satisfy the ordinary differential equations:

$$
\begin{aligned}
C \times A\left(\epsilon_{f, t}\right)^{\frac{\alpha_{s}}{\hat{\alpha}_{s}-\alpha_{s}}}-\rho G_{1}\left(\epsilon_{f, t}\right)-\theta_{\epsilon}(\epsilon-1) \frac{d}{d \epsilon} G_{1}\left(\epsilon_{f, t}\right)+\frac{1}{2} \sigma_{\epsilon}^{2} \epsilon \frac{d^{2}}{d \epsilon^{2}} G_{1}\left(\epsilon_{f, t}\right) & =0 \\
C \times A\left(\epsilon_{f, t}\right)^{\frac{\alpha_{s}}{\alpha_{s}-\alpha_{s}}}-\left(\rho+\mu_{H}+\mu_{L}\right) G_{2}\left(\epsilon_{f, t}\right)-\theta_{\epsilon}(\epsilon-1) \frac{d}{d \epsilon} G_{2}\left(\epsilon_{f, t}\right)+\frac{1}{2} \sigma_{\epsilon}^{2} \epsilon \frac{d^{2}}{d \epsilon^{2}} G_{2}\left(\epsilon_{f, t}\right) & =0 .
\end{aligned}
$$


The present value of the re-sale of the capital of projects that are expected to arrive in future is:

$$
\begin{aligned}
N D V F_{s, t} & =\mathbf{E}_{t}\left[\int_{t}^{\infty} \frac{\pi_{\tau}}{\pi_{t}}\left(\int_{\tau}^{\infty} \delta e^{-\delta(u-\tau)} \frac{\pi_{u}}{\pi_{\tau}} x_{\tau} z_{\tau}^{-1} \bar{\lambda}\left(\int_{F_{s}} K_{f, t}^{*} d f\right) d u\right) d \tau\right] \\
& =\mathbf{E}_{t}\left[\int_{t}^{\infty} \frac{\pi_{\tau}}{\pi_{t}} \frac{\delta \bar{\lambda}}{\delta+r-\mu_{x}+\mu_{z}-\sigma_{z}^{2}+\sigma_{x} \gamma_{x}-\sigma_{z} \gamma_{z}} x_{\tau} z_{\tau}^{-1}\left(\int_{F_{s}} K_{f, t}^{*} d f\right) d \tau\right] \\
& =\int_{t}^{\infty} e^{-Q(\tau-t)} \bar{\lambda} M x_{\tau} z_{\tau}^{-1}\left(\int_{F_{s}} K_{f, t}^{*} d f\right) d \tau \\
& =\frac{1}{Q} \bar{\lambda} M x_{t} z_{t}^{-1}\left(\int_{F_{s}} K_{f, t}^{*} d f\right)
\end{aligned}
$$

Expected excess return on the positive demand component $\left(P D V_{s, t}\right)$ :

$$
\begin{aligned}
\frac{1}{d t} \mathbf{E}_{t}\left[R_{t}^{P D V_{s}}\right]-r & =-\operatorname{cov}\left(\frac{d P D V_{s, t}}{P D V_{s, t}}, \frac{d \pi_{t}}{\pi_{t}}\right)=-\operatorname{cov}\left(\frac{d x_{t}}{x_{t}}+\frac{\alpha}{\hat{\alpha}_{s}-\alpha} \frac{d z_{t}}{z_{t}},-\gamma_{x} d B_{x_{t}}-\gamma_{z} d B_{z_{t}}\right) \\
& =-\operatorname{cov}\left(\sigma_{x} d B_{x_{t}}+\frac{\alpha}{\hat{\alpha}_{s}-\alpha} \sigma_{z} d B_{z_{t}},-\gamma_{x} d B_{x_{t}}-\gamma_{z} d B_{z_{t}}\right) \\
& =\sigma_{x} \gamma_{x}+\frac{\alpha_{s}}{\hat{\alpha}_{s}-\alpha_{s}} \sigma_{z} \gamma_{z}
\end{aligned}
$$

Expected excess return on the positive demand components $\left(N D V P_{s, t}\right.$ and $\left.N D V F_{s, t}\right)$ :

$$
\begin{aligned}
& \frac{1}{d t} \mathbf{E}_{t}\left[R_{t}^{N D V P_{s}}\right]-r=-\operatorname{cov}\left(\frac{d N D V P_{s, t}}{N D V P_{s, t}}, \frac{d \pi_{t}}{\pi_{t}}\right)=\sigma_{x} \gamma_{x}-\sigma_{z} \gamma_{z} \\
& \frac{1}{d t} \mathbf{E}_{t}\left[R_{t}^{\left.N D V F_{s}\right]-r}\right.=-\operatorname{cov}\left(\frac{d N D V F_{s, t}}{N D V F_{s, t}}, \frac{d \pi_{t}}{\pi_{t}}\right)=-\operatorname{cov}\left(\frac{d x_{t}}{x_{t}}+\frac{\alpha_{s}}{\hat{\alpha}_{s}-\alpha_{s}} \frac{d z_{t}}{z_{t}},-\gamma_{x} d B_{x_{t}}-\gamma_{z} d B_{z_{t}}\right) \\
&=-\operatorname{cov}\left(\sigma_{x} d B_{x_{t}}+\sigma_{z} \frac{\alpha_{s}}{\hat{\alpha}_{s}-\alpha_{s}} d B_{z_{t}},-\gamma_{x} d B_{x_{t}}-\gamma_{z} d B_{z_{t}}\right) \\
&=\sigma_{x} \gamma_{x}+\frac{\alpha_{s}}{\hat{\alpha}_{s}-\alpha_{s}} \sigma_{z} \gamma_{z}
\end{aligned}
$$


The expected excess return on the investment-goods firm is:

$$
\begin{aligned}
& \frac{1}{d t} \mathbf{E}_{t}\left[R_{t}^{I}\right]-r=\sigma_{x} \gamma_{x}\left(\frac{P D V_{L, t}+P D V_{H, t}-N D V_{L, t}-N D V_{H, t}}{V_{t}^{I}}\right) \\
& +\sigma_{z} \gamma_{z}\left(\frac{\alpha_{L}}{\hat{\alpha}_{L}-\alpha_{L}} \frac{P D V_{L, t}-N D V F_{L, t}}{V_{t}^{I}}+\frac{\alpha_{H}}{\hat{\alpha}_{H}-\alpha_{H}} \frac{P D V_{H, t}-N D V F_{H, f}}{V_{t}^{I}}\right. \\
& \left.-\frac{N D V P_{L, t}+N D V P_{H, t}}{V_{t}^{I}}\right) \\
& =\sigma_{x} \gamma_{x}+ \\
& \sigma_{z} \gamma_{z} \frac{\frac{\alpha_{L}}{\hat{\alpha}_{L}-\alpha_{L}}\left(P D V_{L, t}-N D V F_{L, t}\right)+\frac{\alpha_{H}}{\hat{\alpha}_{H}-\alpha_{H}}\left(P D V_{H, t}-N D V F_{H, t}\right)}{V_{t}^{I}}+ \\
& \sigma_{z} \gamma_{z} \frac{N D V P_{L, t}+N D V P_{H, t}}{V_{t}^{I}}
\end{aligned}
$$

, where I define $N P V_{s, t}=N D V P_{s, t}+N D V F_{s, t}$ for sake of simplicity.

The exposure of the IMC portfolio to each of the aggregate shocks $x$ and IST shock $z$ is:

$$
\begin{aligned}
\beta_{t}^{I M C, z} & =\frac{\operatorname{cov}\left(R_{t}^{I M C}, \frac{d z_{t}}{z_{t}}\right)}{\operatorname{var}\left(\frac{d z_{t}}{z_{t}}\right)}=\frac{\operatorname{cov}\left(\sigma_{z} d B_{z_{t}}\left(I N V_{t}-P V G O R S_{t}\right), \sigma_{z} d B_{z_{t}}\right)}{\operatorname{var}\left(\sigma_{z} d B_{z_{t}}\right)} \\
& =I N V_{t}-P V G O R S_{t} \\
\beta_{t}^{I M C, x} & =\frac{\operatorname{cov}\left(R_{t}^{I M C}, \frac{d x_{t}}{x_{t}}\right)}{\operatorname{var}\left(\frac{d x_{t}}{x_{t}}\right)}=\frac{\operatorname{cov}\left(-\sigma_{x} d B_{x_{t}} C F O_{t} \times L D I F F, \sigma_{x} d B_{x_{t}}\right)}{\operatorname{var}\left(\sigma_{x} d B_{x_{t}}\right)} \\
& =-C F O_{t} \times L D I F F
\end{aligned}
$$

Firm $f^{\prime} s$ exposure to the IMC portfolio is:

$$
\begin{aligned}
\beta_{f, t}^{I M C}= & \frac{\operatorname{cov}\left(R_{f, t}, R_{t}^{I M C}\right)}{\operatorname{var}\left(R_{t}^{I M C}\right)} \\
= & \frac{\operatorname{cov}\left(\sigma_{x} d B_{x_{t}} \frac{C F I_{f, t}+R S_{f, t}+P V G O_{f, t}}{V_{f, t}},-\sigma_{x} d B_{x_{t}} C F O_{t} \times L D I F F\right)}{\operatorname{var}\left(R_{t}^{I M C}\right)} \\
& +\frac{\operatorname{cov}\left(\sigma_{z} d B_{x_{t}}\left(\frac{\alpha_{s}}{\hat{\alpha}_{s}-\alpha_{s}} \frac{P V G O_{f, t}}{V_{f, t}}-\frac{R S_{f, t}}{V_{f, t}}\right), \sigma_{z} d B_{z, t}\left(I N V_{t}-P V G O R S_{t}\right)\right)}{\operatorname{var}\left(R_{t}^{I M C}\right)} \\
= & -\frac{\sigma_{x}^{2}\left(\frac{C F I_{f, t}+R S_{f, t}+P V G O_{f, t}}{V_{f, t}}\right) C F O_{t} \times L D I F F}{\sigma_{x}^{2}\left(C F O_{t} \times L D I F F\right)^{2}+\sigma_{z}^{2}\left(I N V_{t}-P V G O R S_{t}\right)^{2}} \\
& +\frac{\sigma_{z}^{2}\left(\frac{\alpha_{s}}{\sigma_{x}^{2}\left(C V \alpha_{s}\right.} \frac{P V O_{f, t}}{V_{f, t}}-\frac{R S_{f, t}}{V_{f, t}}\right)\left(I N V_{t}-P V G O R S_{t}\right)}{L I F F)^{2}+\sigma_{z}^{2}\left(I N V_{t}-P V G O R S_{t}\right)^{2}}
\end{aligned}
$$




\section{REFERENCES}

Fisher, Jonas DM, 2006, The dynamic effects of neutral and investment-specific technology shocks, Journal of political Economy 114, 413-451.

Garlappi, Lorenzo, and Zhongzhi Song, 2016, Can investment shocks explain the cross-section of equity returns?, Management Science .

Garlappi, Lorenzo, and Zhongzhi Song, 2018, An exposure to investment shocks: a new approach based on investment data, Working paper, University of British Columbia .

Gomes, Joao F, Leonid Kogan, and Motohiro Yogo, 2009, Durability of output and expected stock returns, Journal of Political Economy 117.

Greenwood, Jeremy, Zvi Hercowitz, and Gregory W Huffman, 1988, Investment, capacity utilization, and the real business cycle, The American Economic Review 402-417.

Greenwood, Jeremy, Zvi Hercowitz, and Per Krusell, 1997, Long-run implications of investmentspecific technological change, The American Economic Review 342-362.

Greenwood, Jeremy, Zvi Hercowitz, and Per Krusell, 2000, The role of investment-specific technological change in the business cycle, European Economic Review 44, 91-115.

Justiniano, Alejandro, Giorgio E Primiceri, and Andrea Tambalotti, 2010, Investment shocks and business cycles, Journal of Monetary Economics 57, 132-145.

Kogan, Leonid, and Dimitris Papanikolaou, 2013, Firm characteristics and stock returns: The role of investment-specific shocks, Review of Financial Studies 26, 2718-2759.

Kogan, Leonid, and Dimitris Papanikolaou, 2014, Growth opportunities, technology shocks, and asset prices, The Journal of Finance 69, 675-718.

Papanikolaou, Dimitris, 2011, Investment shocks and asset prices, Journal of Political Economy 119, 639-685. 


\section{Tables}

Table I

Factors: Correlation Matrix

The table shows the pairwise correlation coefficients between monthly returns of the IMC portfolio, market portfolio and the Fama and French (1993) SMB and HML factors. The time period is from 1970 to 2015.

\begin{tabular}{lcccc}
\hline & IMC & Market & SMB & HML \\
\cline { 2 - 5 } IMC & 1.00 & 0.45 & -0.25 & 0.45 \\
Market & 0.45 & 1.00 & -0.32 & 0.29 \\
HML & -0.25 & -0.32 & 1.00 & -0.24 \\
SMB & 0.45 & 0.29 & -0.24 & 1.00 \\
\hline
\end{tabular}

Table II

Portfolio Return Properties of All Firms in the Consumption-Goods Sector Sorted by $\beta^{I M C}$

The table shows the average excess returns (panel A) and the estimates of the CAPM (panel B) and Fama and French (1993) model (panel C) for portfolios sorted by $\beta^{I M C}$. Panel D shows the median sorting $\beta^{I M C}$ of the five portfolios as well as the portfolios' post-ranking exposures to the IMC portfolio. Stocks are sorted into five portfolios at the end of each June based on $\beta^{I M C}$ estimated from a univariate regression of monthly stock returns over the last 60 months. Portfolios are value-weighted. HL indicates a long-short portfolio with a long position in portfolio 5 and a short position in portfolio 1 . The time period is from 1970 to 2015 . *** Significant at 1 percent level. ** Significant at 5 percent level. ${ }^{*}$ Significant at 10 percent level.

\begin{tabular}{|c|c|c|c|c|c|c|}
\hline & 1 & 2 & 3 & 4 & 5 & HL \\
\hline Mean & $\begin{array}{c}8.71^{* * *} * \\
(1.87)\end{array}$ & $\begin{array}{r}\mathrm{Pa} \\
8.11 * * * \\
(2.2) \\
\end{array}$ & $\begin{array}{c}\text { 1 A. Avea } \\
7.67^{* * *} \\
(2.41)\end{array}$ & $\begin{array}{c}\text { excess } \mathrm{r} \\
6.93^{* * *} * \\
(2.26)\end{array}$ & $\begin{array}{l}\text { urn } \\
7.66^{* *} \\
(3.48) \\
\end{array}$ & $\begin{array}{l}-1.06 \\
(2.68) \\
\end{array}$ \\
\hline $\begin{array}{l}\alpha \\
\text { Market } \\
R^{2}\end{array}$ & $\begin{array}{c}3.42^{* * *} * \\
(0.98) \\
0.73^{* * *} * \\
(0.03) \\
73.18 \\
\end{array}$ & $\begin{array}{c}1.56 * * \\
(0.71) \\
0.91 * * * \\
(0.02) \\
87.8\end{array}$ & $\begin{array}{c}\text { Panel } \\
0.28 \\
(0.99) \\
1.02^{* * *} \\
(0.02) \\
83.4 \\
\end{array}$ & $\begin{array}{c}\text { CAPM } \\
-1.79 \\
(1.23) \\
1.21^{* * *} \\
(0.02) \\
86.18 \\
\end{array}$ & $\begin{array}{c}-3.06 \\
(1.92) \\
1.48^{* * *} \\
(0.05) \\
73.28 \\
\end{array}$ & $\begin{array}{c}-6.48 * * * \\
(2.43) \\
0.75 * * * \\
(0.07) \\
28.67\end{array}$ \\
\hline $\begin{array}{l}\alpha \\
\text { Market } \\
S M B \\
H M L \\
R^{2}\end{array}$ & $\begin{array}{c}3.94 * * * \\
(0.88) \\
0.79 * * * \\
(0.02) \\
-0.33^{* * *} \\
(0.03) \\
-0.01 \\
(0.04) \\
79.65\end{array}$ & $\begin{array}{c}\text { Pan } \\
1.54^{* *} \\
(0.77) \\
0.93^{* * *} \\
(0.02) \\
-0.12^{* * *} \\
(0.03) \\
0.04 \\
(0.03) \\
88.58 \\
\end{array}$ & $\begin{array}{c}\text { C. Fama } \\
0.8 \\
(1.04) \\
1.0^{* * *} \\
(0.03) \\
0.02 \\
(0.08) \\
-0.1^{*} \\
(0.06) \\
83.78 \\
\end{array}$ & $\begin{array}{c}\text { d French } \\
-1.92 \\
(1.17) \\
1.16^{* * *} \\
(0.03) \\
0.22^{* * *} \\
(0.04) \\
-0.04 \\
(0.05) \\
87.53 \\
\end{array}$ & $\begin{array}{c}993) \\
-1.46 \\
(1.74) \\
1.3^{* * *} \\
(0.04) \\
0.54^{* * *} \\
(0.07) \\
-0.46^{* * *} \\
(0.09) \\
81.62 \\
\end{array}$ & $\begin{array}{c}-5.39^{* * *} * \\
(2.06) \\
0.51^{* * *} \\
(0.06) \\
0.87^{* * *} \\
(0.08) \\
-0.45^{* * *} \\
(0.11) \\
52.89 \\
\end{array}$ \\
\hline $\begin{array}{l}\text { sorting } \\
\beta^{I M C} \\
I M C\end{array}$ & $\begin{array}{c}-0.16 \\
0.1 \\
(0.06) \\
\end{array}$ & $\begin{array}{c}\text { Panel D } \\
0.58 \\
0.5 * * * \\
(0.08)\end{array}$ & $\begin{array}{c}\text { Sorting an } \\
1.02 \\
0.7^{* * *} \\
(0.1)\end{array}$ & $\begin{array}{c}\text { post-sort } \\
1.56 \\
1.04^{* * *} * \\
(0.09)\end{array}$ & $\begin{array}{c}\operatorname{g~} \beta^{I M C} \\
2.8 \\
1.5^{* * *} \\
(0.1)\end{array}$ & $\begin{array}{c}1.4^{* * * *} \\
(0.08)\end{array}$ \\
\hline
\end{tabular}




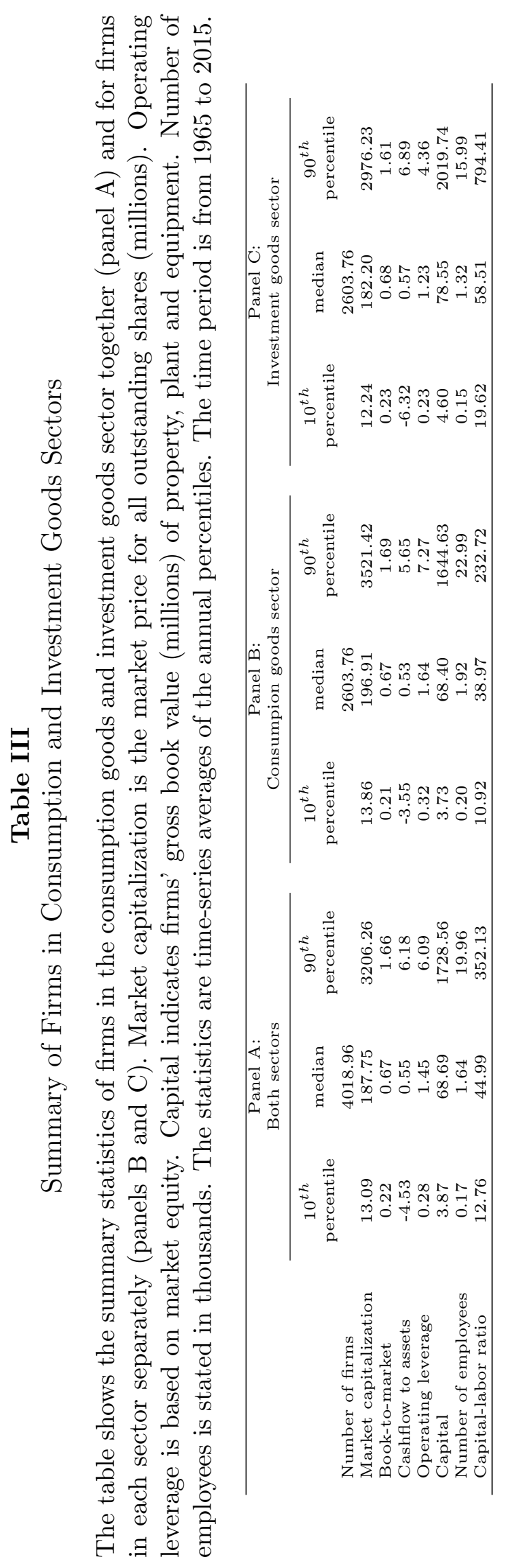




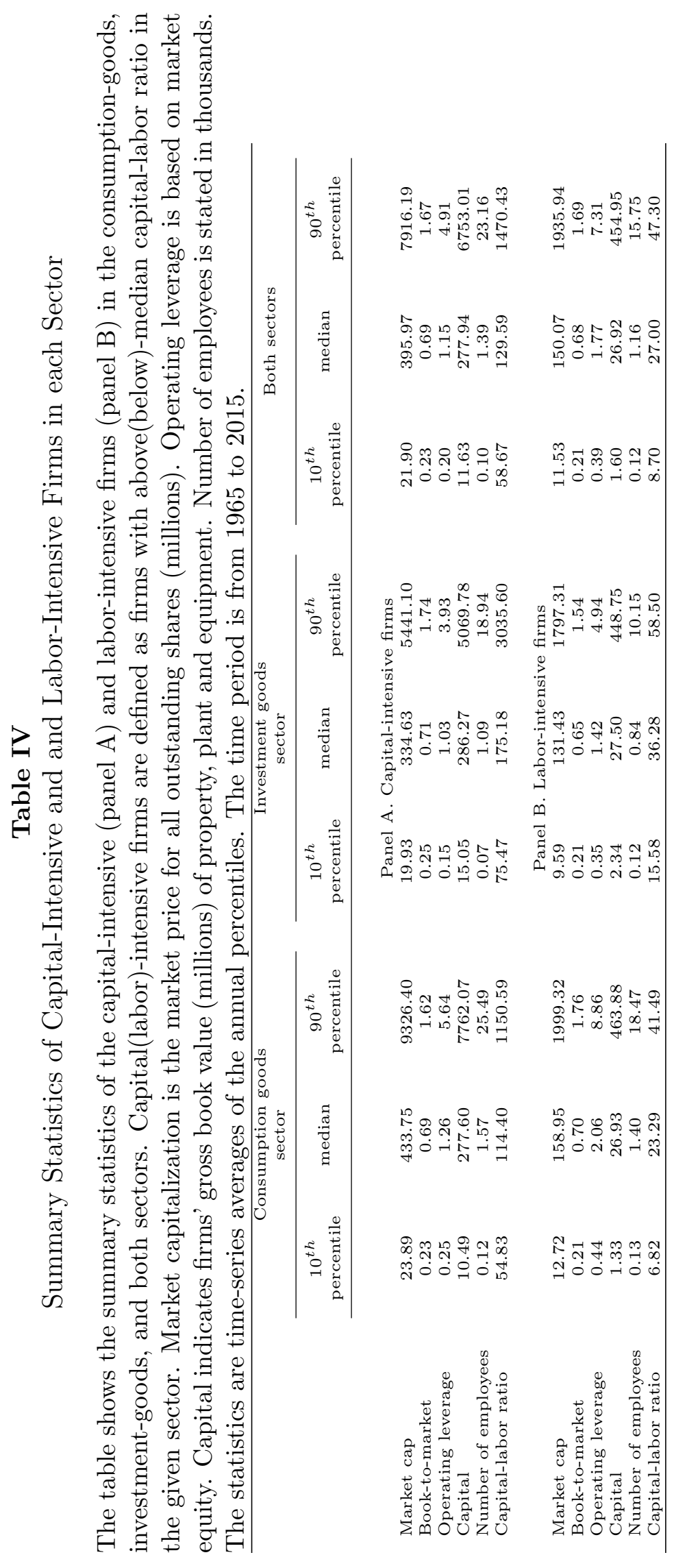




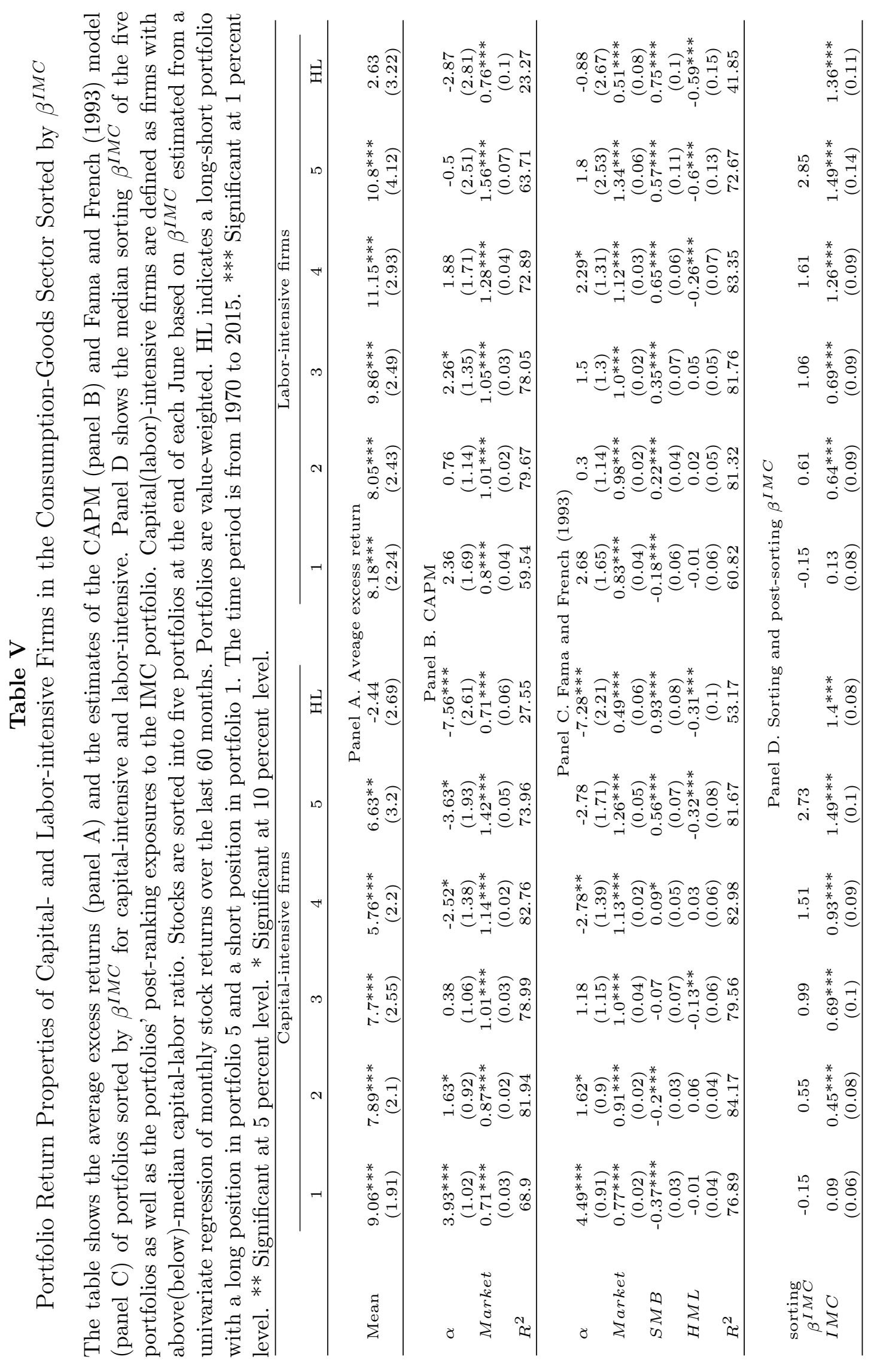


Table VI

Exposure of Firm-Value Components to Both Types of Shocks and to the IMC Portfolio

The table shows how the firm's value components affect firm's exposure to the shocks $x_{t}, z_{t}$, and to the IMC portfolio. The value components are in rows and the shocks (the IMC portfolio) are in columns.

\begin{tabular}{|c|c|c|c|}
\hline & $x_{t}$ & $z_{t}$ & IMC \\
\hline$\frac{C F O_{f, t}}{V_{f, t}}$ & $(1-\mathrm{v})$ & none & $(1-\mathrm{v})$ \\
\hline$\frac{P V G O_{f, t}}{V_{f, t}}$ & none & $\left(\frac{\alpha_{s}}{\hat{\alpha}_{s}-\alpha_{s}}\right)$ & $\left(\frac{\alpha_{s}}{\hat{\alpha}_{s}-\alpha_{s}}\right)$ \\
\hline$\frac{R S_{f, t}}{V_{f, t}}$ & none & -1 & -1 \\
\hline
\end{tabular}

Table VII

Panel Regressions of Firms $\beta^{I M C}$ on Firms' Market-to-Book Ratio, Capital, and Operating Leverage

The table shows the results of panel regression $\beta_{f, t}^{I M C}=$ constant $+\xi_{1}$ market-to-book + $\xi_{2} \frac{\text { capital }}{\text { marketcap }}+\xi_{3}$ Operating leverage $+\epsilon_{f, t}$ for all firms in the consumption goods sector and for capital- and labor-intensive firms separately. The last two columns use the ratio of the selling, general and administrative expenses to market capitalization as an alternative measure of operating leverage. The panel regressions include industry and year fixed effects with industries defined at 4-digit SIC code. Standard errors are clustered at 3-digit SIC code and account for heteroscedasticity. The time period is from 1970 to 2015. *** Significant at 1 percent level. ** Significant at 5 percent level. * Significant at 10 percent level.

\begin{tabular}{lccccc}
\hline & All firms & $\begin{array}{c}\text { Capital- } \\
\text { intensive firms }\end{array}$ & $\begin{array}{c}\text { Labor- } \\
\text { intensive firms }\end{array}$ & $\begin{array}{c}\text { Capital- } \\
\text { intensive firms }\end{array}$ & $\begin{array}{c}\text { Labor- } \\
\text { intensive firms }\end{array}$ \\
\hline Market-to-book & $0.005^{* *}$ & $0.009^{* * *}$ & 0.003 & $0.009^{* * *}$ & 0.004 \\
& $(0.002)$ & $(0.003)$ & $(0.003)$ & $(0.003)$ & $(0.003)$ \\
capital & $0.021^{* * *}$ & $0.032^{* * *}$ & 0.001 & $0.034^{* * *}$ & -0.002 \\
market cap & $(0.007)$ & $(0.007)$ & $(0.011)$ & $(0.007)$ & $(0.009)$ \\
Operating & $0.009^{* * *}$ & 0.006 & $0.009^{* *}$ & & \\
leverage & $(0.003)$ & $(0.005)$ & $(0.003)$ & & \\
\multicolumn{1}{r}{ ssga } & & & & 0.026 & $0.051^{* * *}$ \\
market cap & & & & $0.020)$ & $(0.012)$ \\
\hline Industry FE & Yes & Yes & Yes & Yes & Yes \\
Year FE & Yes & Yes & Yes & Yes & Yes \\
$N$ & 120374 & 57693 & 62729 & 57693 & 62729 \\
$R^{2}$ & 0.311 & 0.347 & 0.315 & 0.347 & 0.315 \\
\hline
\end{tabular}




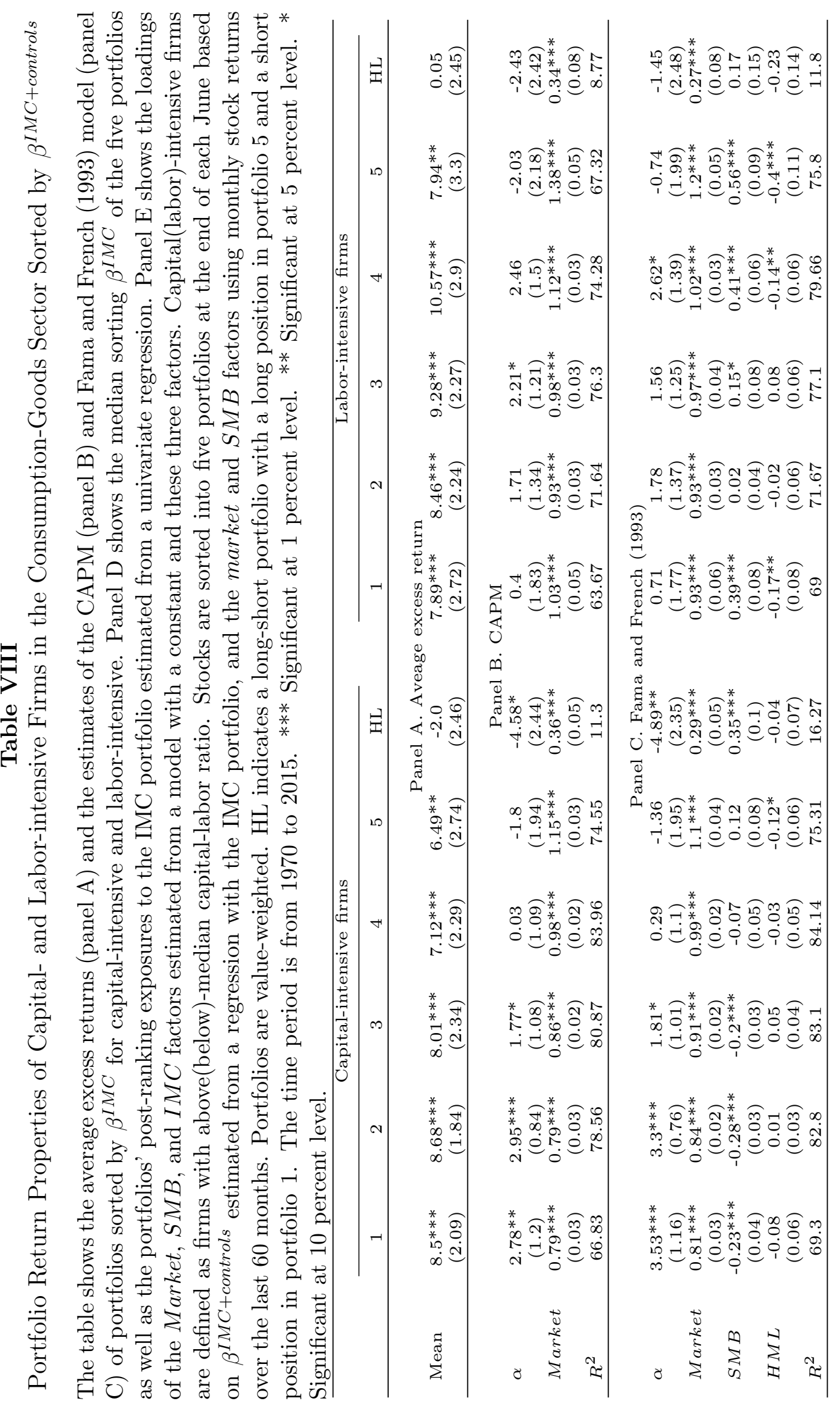




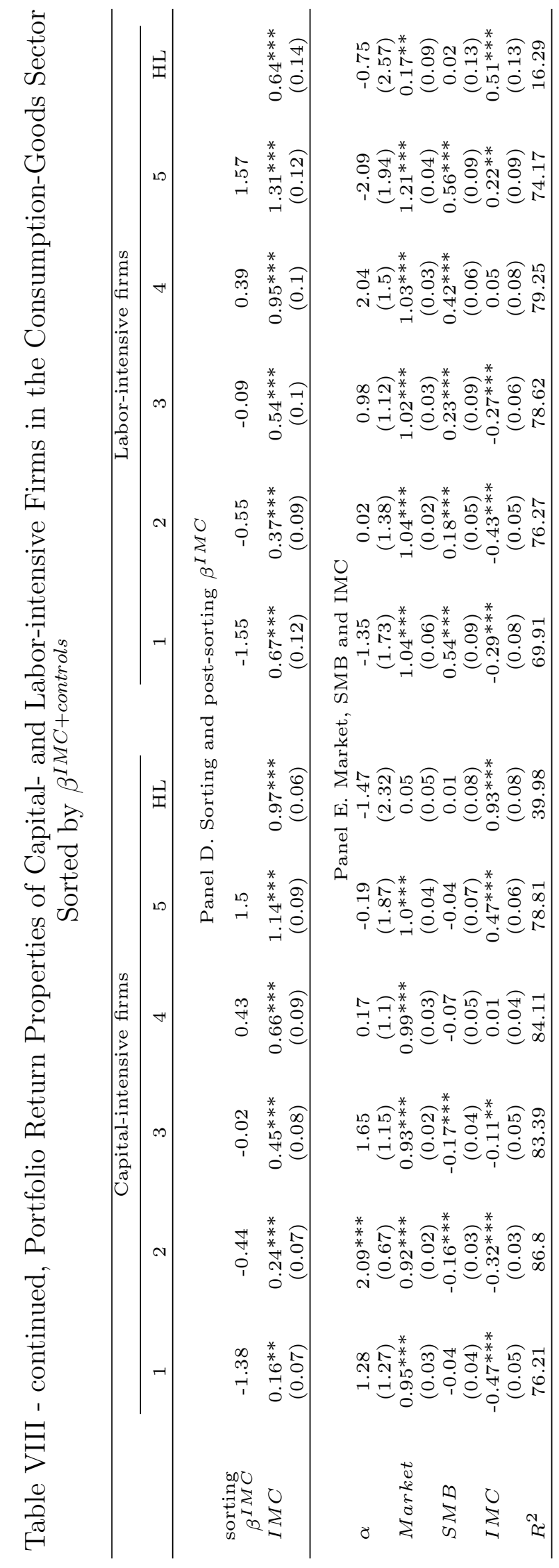


Table IX

Parameter Values for Model Calibration

\begin{tabular}{|c|c|c|}
\hline Parameter & Symbol & Value \\
\hline \multicolumn{3}{|l|}{ Aggregate shocks } \\
\hline Mean growth rate of agg. productivity shock & $\mu_{x}$ & 0.01 \\
\hline Volatility of agg. productivity shock & $\sigma_{x}$ & 0.12 \\
\hline Mean growth rate of the IST shock & $\mu_{z}$ & 0.001 \\
\hline Volatility of the IST shock & $\sigma_{z}$ & 0.033 \\
\hline \multicolumn{3}{|l|}{ Idiosyncratic shocks } \\
\hline Persistence of the firm-specific shock & $\theta_{\epsilon}$ & 0.35 \\
\hline Volatility of the firm-specific shock & $\sigma_{\epsilon}$ & 0.20 \\
\hline Persistence of the project-specific shock & $\theta_{u}$ & 0.50 \\
\hline Volatility of the project-specific shock & $\sigma_{u}$ & 1.50 \\
\hline \multicolumn{3}{|l|}{ Project arrival and depreciation } \\
\hline Project depreciation rate & $\delta$ & 0.10 \\
\hline Arrival rate parameter 1 & $\mu_{\lambda}$ & 2.00 \\
\hline Arrival rate parameter 2 & $\hat{\sigma_{\lambda}}$ & 2.00 \\
\hline Transition probability into high-growth state & $\mu_{H}$ & 0.075 \\
\hline Transition probability into low-growth state & $\mu_{L}$ & 0.160 \\
\hline Project arrival rate in the high-growth state & $\lambda_{H}$ & 2.35 \\
\hline \multicolumn{3}{|l|}{ Stochastic discount factor } \\
\hline Risk-free rate & $\mathrm{r}$ & 0.03 \\
\hline Price of risk of the aggregate productivity shock & $\gamma_{x}$ & 0.69 \\
\hline Price of the IST shock & $\gamma_{z}$ & -0.35 \\
\hline \multicolumn{3}{|l|}{ Capital and labor-intensity (production function) } \\
\hline Capital-intensity of capital-intensive firms & $\alpha_{H}$ & 0.775 \\
\hline Capital-intensity of labor-intensive firms & & 0.575 \\
\hline Labor intensity of capital-intensive firms & $1-\hat{\alpha}_{L}$ & 0.075 \\
\hline Labor intensity of labor-intensive firms & $1-\hat{\alpha}_{H}$ & 0.275 \\
\hline \multicolumn{3}{|l|}{ 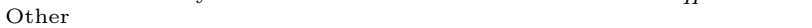 } \\
\hline Profit margin of the investment sector & $\phi$ & 0.07 \\
\hline Aggregate wage factor & $w$ & 0.007 \\
\hline Labor force with flexible wage & $\mathrm{v}$ & 0.25 \\
\hline Leverage difference & LDIFF & -10 \\
\hline
\end{tabular}


Table X

Simulated Moments

The table shows the empirical moments, the calibrated moments from the Kogan and Papanikolaou (2014) model (KP) and my extended model (Capital-intensity model). Most of the empirical moments are from Kogan and Papanikolaou (2014). Relative capital-labor ratio is the capital-labor ratio of capital-intensive firms relative to the same ratio of labor-intensive firms. IQR indicates the interquartile range. Relative capital labor ratio is the capital-labor ratio of capital intensive firms divided by capital-labor ratio of labor-intensive firms. The moments for the extended model (Capital-intensity model) are medians across simulations of the model.

\begin{tabular}{|c|c|c|c|}
\hline & Data & KP model & Capital-intensity model \\
\hline \multicolumn{4}{|l|}{ Aggregate moments } \\
\hline Agg. dividend growth, mean & 0.025 & 0.017 & 0.017 \\
\hline Agg. dividend growth, std. & 0.118 & 0.150 & 0.206 \\
\hline Agg. investment growth, mean & 0.047 & 0.041 & 0.020 \\
\hline Agg. investment growth, std. & 0.157 & 0.171 & 0.200 \\
\hline \multicolumn{4}{|l|}{ Asset pricing moments } \\
\hline Mean excess return of market portfolio & 0.059 & 0.056 & 0.073 \\
\hline Volatility of market portfolio return & 0.161 & 0.164 & 0.142 \\
\hline Mean return of the IMC portfolio & -0.014 & -0.039 & -0.015 \\
\hline Volatility of the IMC portfolio return & 0.113 & 0.115 & 0.312 \\
\hline Correlation between the IMC and market return & 0.45 & NA & 0.549 \\
\hline Correlation between the IMC return investment shock & NA & 1 & 0.834 \\
\hline Correlation between the IMC return aggregate shock & NA & 0 & 0.397 \\
\hline \multicolumn{4}{|l|}{ Cross-sectional moments } \\
\hline Firms investment rate, median & 0.112 & 0.121 & 0.156 \\
\hline Firms investment rate, IQR & 0.157 & 0.168 & 0.092 \\
\hline Cash flows-to-capital, median & 0.160 & 0.249 & 0.170 \\
\hline Cash flows-to-capital, IQR & 0.234 & 0.222 & 0.151 \\
\hline Tobin's Q, median & 1.412 & 1.988 & 1.714 \\
\hline Tobin's Q, IQR & 2.981 & 1.563 & 0.600 \\
\hline Relative firm size, median & 0.200 & 0.701 & 0.652 \\
\hline Relative firm size, IQR & 0.830 & 0.882 & 0.936 \\
\hline Correlation betweem Tobin's $Q$ and relative firm size & 0.160 & -0.369 & -0.287 \\
\hline \multicolumn{4}{|l|}{ Capital- vs. labor-intensive firms } \\
\hline Relative capital-labor ratio, median & 4.912 & NA & 4.959 \\
\hline
\end{tabular}

Table XI

Simulated Stock Returns

The table shows the properties of the portfolio returns of firms sorted by $\beta^{I M C}$ for capital-intensive (panel A) and labor-intensive firms (panel B) simulated in the extended model. Stocks are sorted into 10 portfolios based on their $\beta^{I M C}$ estimated from a univariate regression. The average sorting $\beta^{I M C}$ within each portfolio are reported in the corresponding row. $\alpha$ is the annualized average excess return estimated in a univariate regression with market excess return. $\beta$ denotes the portfolios' exposure to the market excess return. $\beta^{I M C}$ is the portfolios' post-ranking exposure to the IMC portfolio estimated from a univariate regression. $\beta^{z}$ denotes the true exposure to the investment shock $z_{t}$. The reported results are medians across the simulations.

\begin{tabular}{|c|c|c|c|c|c|c|c|c|c|c|c|}
\hline & $\mathrm{p} 1$ & $\mathrm{p} 2$ & p3 & $\mathrm{p} 4$ & p5 & p6 & $\mathrm{p} 7$ & $\mathrm{p} 8$ & p9 & $\mathrm{p} 10$ & HL \\
\hline \multicolumn{12}{|c|}{ Panel A. Capital-intensive firms } \\
\hline Average excess return & 8.052 & 7.846 & 7.741 & 7.659 & 7.308 & 7.010 & 6.706 & 6.481 & 5.510 & 4.309 & -6.708 \\
\hline$\alpha$ & -2.734 & -3.123 & -3.349 & -3.490 & -3.903 & -4.387 & -4.797 & -5.358 & -6.497 & -8.162 & -5.269 \\
\hline & 0.895 & 0.894 & 0.903 & 0.910 & 0.921 & 0.927 & 0.943 & 0.958 & 0.986 & 1.030 & 0.129 \\
\hline $\begin{array}{l}\text { sorting } \\
\beta^{I M C}\end{array}$ & 0.149 & 0.234 & 0.267 & 0.299 & 0.329 & 0.360 & 0.396 & 0.444 & 0.514 & 0.672 & \\
\hline$\beta^{I M C}$ & 0.188 & 0.185 & 0.198 & 0.206 & 0.222 & 0.236 & 0.259 & 0.289 & 0.350 & 0.446 & 0.238 \\
\hline$\beta^{z}$ & 0.613 & 0.633 & 0.714 & 0.820 & 0.956 & 1.095 & 1.329 & 1.588 & 2.110 & 2.944 & 2.309 \\
\hline \multicolumn{12}{|c|}{ Panel B. Labor-intensive firms } \\
\hline Average excess return & 11.638 & 11.644 & 11.305 & 11.345 & 11.171 & 11.182 & 10.784 & 10.108 & 9.532 & 8.731 & -6.219 \\
\hline$\alpha$ & -0.168 & -0.635 & -0.754 & -0.772 & -0.899 & -1.080 & -1.516 & -2.025 & -2.678 & -3.871 & -3.695 \\
\hline$\beta$ & 0.993 & 0.992 & 0.997 & 0.993 & 1.002 & 1.003 & 1.001 & 1.006 & 1.003 & 1.021 & 0.021 \\
\hline $\begin{array}{l}\text { sorting } \\
\beta^{I M C}\end{array}$ & 0.090 & 0.190 & 0.230 & 0.263 & 0.293 & 0.322 & 0.352 & 0.388 & 0.443 & 0.603 & \\
\hline$\beta^{I M C}$ & 0.193 & 0.179 & 0.188 & 0.195 & 0.195 & 0.202 & 0.216 & 0.233 & 0.272 & 0.349 & 0.142 \\
\hline$\beta^{z}$ & 0.443 & 0.333 & 0.377 & 0.384 & 0.489 & 0.557 & 0.679 & 0.853 & 1.207 & 1.807 & 1.383 \\
\hline
\end{tabular}

